\section{THE LITHIC ASSEMBLAGE}

\subsection{Introduction}

The excavations undertaken at East Barns produced a total of 30,142 lithic artefacts. The overwhelming majority of these were directly associated with the house and its surrounding deposits. The assemblage was retrieved by a combination of hand excavation and the on-site wet-sieving of all excavated deposits. This enabled a near $100 \%$ retrieval of artefacts to be undertaken. A more detailed description is given in the site methodology.

All material was catalogued using the typologies established during the excavations undertaken at Kinloch, Rhum (Wickham-Jones 1990) and the Southern Hebrides Mesolithic Project (SHMP) (Finlayson et al 2000). Information was also shared with the contemporary excavation at Howick, Northumberland (Pedersen 2007). This enabled a greater degree of standardisation to be employed for technical terms and descriptions.

\subsection{Lithic raw materials}

The lithic assemblage was dominated by flint (85\%), with various supplementary materials such as cherts (8\%), chalcedonies (1\%) and quartz (5\%) (Table 2).

This range of raw materials is common to Mesolithic sites along the east coast of Scotland such as Morton, Fife (Coles 1971), Cramond (Lawson 2001; Saville 2004) and Echline Fields (Robertson et al 2013). At East Barns the raw materials appear to be derived from the immediate locale. Here glacial tills overlie carboniferous sedimentary rocks of sandstones, shales, grits and limestones, materials rich in chalcedonic silicas (Bown \& Shipley 1982).
Some caution must be applied in the identification of the raw materials recovered given the large percentage of fine fraction material present within the assemblage. It is notable that many of the cherts and chalcedonies are fine-grained and 'flint-like' in form. Therefore, a general macroscopic analysis of the material will likely provide potential for misidentification (Saville 2004: 213). WickhamJones \& Hardy (2004: 20) have reported that this often happens where a wide variety of chalcedonic silicas occur within a single vicinity. At the excavation of the Mesolithic site of Camas Daraich on Skye (Wickham-Jones 2004c) this problem was alleviated by cataloguing all such material as generic chalcedonic silica. At East Barns most of the larger pieces were easily identifiable and as such a more precise identification was attempted in cataloguing the assemblage while recognising the probability for mistakes in the smaller fractions.

\subsubsection{Flint}

Flint dominates the assemblage (25,553 pieces/85\%) and is generally fine-grained and of relatively good quality. Most of the flint appears to have been derived from small to medium sub-angular nodules with a smooth, hard cortex. Unlike sites such as Killellan Farm (Saville 2005: 99) where numerous such nodules were retrieved, only one intact example was recovered. Information on the types of flint nodules used at East Barns must therefore be gleaned by adding the 10 struck or tested pieces, together with inferences gathered from the 16 split nodules and the core types (see Section 4.4, Primary technology).

Due to the irregular shape and small size of the

Table 2 The lithic assemblage: raw materials

\begin{tabular}{lrrrrrr} 
& Flint & Chert & Chalcedony & Quartz & Quartzite & Other \\
Debitage & 24132 & 2333 & 303 & 1542 & 33 & 1 \\
\hline Pebbles & 28 & 6 & 3 & 73 & 4 & 1 \\
\hline Cores & 390 & 63 & 11 & 53 & 1 & 0 \\
\hline Retouched & 288 & 37 & 11 & 4 & 0 & 0 \\
\hline Microliths & 379 & 67 & 11 & 0 & 0 & 0 \\
\hline Scrapers & 336 & 20 & 9 & 3 & 0 & 0 \\
\hline Totals & 25553 & 2526 & 348 & 1675 & 38 & 2
\end{tabular}


nodules, many of the pieces show signs of cortication. Using the SHMP classificatory system for describing condition, this allowed 1,116/4\% of the flint within the assemblage to be assessed. The majority of these pieces $(956 / 85.6 \%)$ showed the presence of hard, smooth, water-rolled cortex, although occasional pieces were chalkier in appearance. These water-rolled artefacts were most probably obtained from the nearby shoreline. The remaining pieces $(160 / 14.3 \%)$ had the pitted appearance characteristic of glacial flint obtained from local till deposits. Very few pieces were abraded, and this is probably a result of the site having escaped modern farming activity. Flaws were evident in many of the larger pieces in the form of voids, fossils and other impurities which often altered the shape of the nodule significantly and in the case of core pieces frequently led to their early abandonment (see Section 4.4, Primary technology).

The flint in its fresh state $(7,373 / 29 \%)$ is generally pale to medium grey in colour. Smaller quantities of yellow, red, brown and translucent dark brown flint redolent of chalk-borne deposits are also present. Patination occurs in 4,501/18\% of the pieces. This ranges from slight cream-coloured 'blooms' to a matt white. In some extreme cases this appears to have led to a loss of both weight and texture.

The flint is undoubtedly local in origin. Although mainland Scotland has an apparent lack of in situ flint deposits, flint pebbles have a widespread distribution around the coast. Significant chalk deposits are also known to underlie the North Sea (Gemmell \& Kesel 1977: 66). Similarly, glacial till deposits containing flint, such as the Buchan gravels, are also known. The erosion of these sources by marine and glacial action (Piggott \& Powell 1949: 160) has led to the creation of many such derived deposits along the length of the east coast, with a concentration known to exist in the East Barns locale (Wickham-Jones \& Collins 1978). These flints are often characterised by their small size, grey and yellow colouration (Gemmell \& Kesel 1977: 66) and common flaws and irregularities (WickhamJones 1986: 1).

It is likely that the majority of the assemblage is composed of material that was previously eroded into the sea from the local glacial till and then redistributed on the shoreline. The tendency for such till deposits to be mixed with other materials
(Wickham-Jones 1986, 2) such as chert, chalcedony and quartz would support this origin given the noted similarities in their size and condition. A smaller proportion of the flint may also have been derived from submerged chalk deposits and from tills that are also now covered by the North Sea. Other sources of raw material would include locally available river cuts and exposures. The evaluation of the site area undertaken in 2001 also revealed raised beach deposits located to the south-east of the excavation area bordering the present-day dune system. However, these were probably not contemporary with the site. Numerous small and medium-sized flint nodules can still be obtained along the coastline at East Barns. These nodules probably represent the ongoing erosion of both submerged and coastal deposits.

Approximately $49 \%$ of the flint assemblage appears to have undergone some form of heat alteration such as a colour change, crazing and fracturing. There is the possibility that this percentage may be even higher. In experimental work on the heat treatment of flint undertaken at Kinloch, Rhum (Finlayson 1990a: 53) many intensely heated pieces were found not to display such visible evidence.

\subsubsection{Chert}

Chert is the most common of the supplementary raw materials used at East Barns (2,526/8\%). The material assessed (182 pieces), showed that a slightly higher proportion of chert than flint appeared to have a pitted exterior surface $(34.6 \% / 63)$. This would suggest that a greater proportion of the chert was acquired directly from the local glacial tills. However, the majority was again most probably obtained from the shoreline. The 106 primary pieces suggest that in common with the other raw materials, initial decortication and reduction took place on site.

Chert occurs throughout Scotland and is particularly common in the Southern Uplands. This material not only forms a major component of inland Mesolithic assemblages across the Scottish Borders and south-west Scotland (Mulholland 1970; Affleck 1986; Finlayson 1990b; Saville 1994; Warren 2005) but also appears to dominate Mesolithic coastal assemblages along the Forth (Robertson et al 2013; Saville 2008; Engl 2012). 
The majority of the chert within the assemblage can be described as being of 'Southern Uplands' type. This is often fine-grained and 'flint-like' and has a wide range of colour variations from a common blue-grey to grey-green, brown and dark purple (Ballin \& Johnson 2005).

Chert, like flint and chalcedony, is a silicate found in calcareous sedimentary rocks and occurs in stratified or nodular forms. Like flint, the distribution, colour and form of chert is affected by post-diagenetic factors and fine-grained cherts such as the Southern Uplands type can be found in all carboniferous limestones (Hind 1998: 1). Nearby Chapel Point has been recorded as a prominent source of small dark grey chert lenticules found in limestone (Wickham-Jones \& Collins 1978: 14). Numerous small nodules of chert were observed both on the present-day shoreline and within the till deposits encountered during the archaeological works at East Barns. There is evidence in southern Scotland that cherts were obtained from both primary and derived sources (Saville 1994: 59), with several quarry sites being identified within the region (Warren 2007: 146).

As with the flint, the chert assemblage is affected by the presence of numerous flaws and inclusions. Fifty-one pieces were identified as heat affected. The burning of the chert resulted in the discoloration of the pieces together with an increased friability. As with flint, experiments in the burning of chert have generally shown an absence of discoloration. However, it may be that such a change occurs some time after the initial burning (Ballin \& Johnson 2005: 63).

\subsection{Quartz and quartzites}

Quartz accounted for 5.5\% (1,675 pieces) of the total assemblage, with a small amount of quartzite $(0.03 \% / 38)$ also present. The quartz can be characterised by a light grey translucence, a fine grain, and a generally good conchoidal fracture. Out of the total of 1,675 pieces only 178 (10.6\%) were friable and coarse grained. The quartzite pieces on the other hand are medium grey to pale brown in colour and are generally of a quite coarse grain. Where an outer skin was present both materials appeared water-rolled. This was visible on 34.6\% (580 pieces) of the material. Like many of the other raw materials present at East Barns, the quartz/ quartzite was obtained locally, either from the shoreline or raised beach deposits, or from nearby riverine sources. Quartz nodules are today fairly common, both within the till and on the shoreline.

Quartz is found as a common supplement to flint on a wide range of prehistoric sites throughout Scotland, with an understandable preference for finer quality material. Wickham-Jones (1986: 30) states that quartz was generally used only where other, more easily worked, materials were not available. This hierarchy of materials appears not to have been as prevalent or as rigid at East Barns. Here, the high quality of the quartz, combined with its ready availability and the general small size of nodules of all material types made its collection and subsequent use attractive.

\subsubsection{Chalcedony}

Only $348(1.1 \%)$ pieces of chalcedony were recovered. This is probably a slight underestimation given the problems in identification explained above. As with the flint and chert, the chalcedony occurred in nodular form, with evidence of water-rolled skin present on $14 \%$ (50 pieces) of the material. Pitted pieces accounted for $11 \%$ (38 pieces). This is slightly higher than the flint and chert and may indicate a greater exploitation of this material from within the glacial till.

The chalcedony appears in a variety of colours and forms. The majority appear homogeneous and fine-grained. They are largely pale grey in colour with a distinct waxy lustre. Other types include pink and banded agates and jasper.

\subsubsection{Other materials}

Two other raw materials were present within the assemblage. These consisted of a small piece of silicified limestone and a fragment of fossil wood. Both are known supplementary materials on Mesolithic sites.

\subsection{Primary technology (Table 3)}

\subsubsection{Introduction}

The assemblage contains numerous cores and debitage classes relating to artefact manufacture. 
Table 3 The lithic assemblage: character of debitage

\begin{tabular}{lccccccc} 
& Flint & Chert & Chalcedony & Quartz & Quartzite & Other & Total \\
Flakes & 7050 & 973 & 147 & 384 & 23 & 0 & 8577 \\
Regular & 2181 & 374 & 62 & 130 & 6 & 0 & 2753 \\
\hline Irregular & 4583 & 551 & 80 & 240 & 17 & 0 & 5471 \\
& & & & & & & \\
\hline Primary & 650 & 87 & 20 & 66 & 0 & 0 & 823 \\
\hline Secondary & 1576 & 105 & 26 & 92 & 2 & 0 & 1801 \\
\hline Tertiary & 4537 & 734 & 95 & 212 & 21 & 1 & 5600
\end{tabular}

\begin{tabular}{|c|c|c|c|c|c|c|c|}
\hline Bipolar & 13 & 1 & 0 & 7 & 0 & 0 & 21 \\
\hline Fragments & 262 & 43 & 5 & 5 & 0 & 0 & 315 \\
\hline Spalls & 12 & 2 & 0 & 1 & 0 & 0 & 15 \\
\hline $\begin{array}{l}\text { Rejuvenation } \\
\text { flakes }\end{array}$ & 249 & 42 & 9 & 2 & 0 & 0 & 302 \\
\hline Blades & 1175 & 151 & 27 & 0 & 0 & 0 & 1354 \\
\hline Primary & 5 & 0 & 0 & 0 & 0 & 0 & 5 \\
\hline Secondary & 185 & 12 & 3 & 0 & 0 & 0 & 200 \\
\hline Tertiary & 985 & 139 & 24 & 0 & 0 & 0 & 1149 \\
\hline Small fraction & 14433 & 765 & 80 & 713 & 0 & 1 & 15992 \\
\hline Primary & 64 & 4 & 0 & 27 & 0 & 0 & 95 \\
\hline Secondary & 227 & 10 & 9 & 15 & 0 & 0 & 261 \\
\hline Tertiary & 14142 & 751 & 71 & 671 & 0 & 1 & 15636 \\
\hline Chunks & 1215 & 398 & 40 & 324 & 10 & 0 & 1987 \\
\hline Fragments & 9 & 3 & 0 & 120 & 0 & 0 & 132 \\
\hline Cores & 390 & 64 & 11 & 52 & 1 & 0 & 518 \\
\hline Platform & 337 & 51 & 10 & 21 & 1 & 0 & 421 \\
\hline Bipolar & 42 & 7 & 1 & 30 & 0 & 0 & 80 \\
\hline Amorphous & 11 & 5 & 0 & 1 & 0 & 0 & 17 \\
\hline Pebbles & 2 & 3 & 3 & 9 & 1 & 1 & 19 \\
\hline Tested pebbles & 10 & 0 & 0 & 21 & 0 & 0 & 31 \\
\hline Split pebbles & 16 & 3 & 0 & 43 & 3 & 0 & 65 \\
\hline
\end{tabular}


This material reflects the initial stages of the chaine opératoire at East Barns. A number of analyses were undertaken in order to obtain a more detailed picture of the assemblage and its character. These analyses were based on those undertaken in the SHMP (Finlayson et al 2000). As a significant percentage of the assemblage was recovered from redeposited contexts infilling the area of the house it was decided to target the in situ occupation deposits both within and immediately surrounding the structure in order to produce as uncontaminated a sample as possible. The analyses focus on the core, blade/flake and fine fraction categories.

\subsubsection{Pebbles, split pebbles and tested pieces}

As mentioned within the Raw materials section (4.2 above), a variety of unmodified and tested pebble artefacts were recovered. These included 28 made on flint, six on chert, three on chalcedony and 73 on quartz (Table 3). The nodules were of a generally small size and largely water-worn.

A mean size of $39.4 \mathrm{~mm} \times 32.7 \mathrm{~mm} \times 21.2 \mathrm{~mm}$ was calculated for the 12 whole and tested nodules. This is at the threshold for undertaking successful platform core knapping (Marshall 2000). It is probable that the platform cores found within the assemblage would have utilised a range of larger nodules than is represented here (see below), as they often display a range of dimensions that exceeds those of the pebbles. A search of the present shoreline found pebbles that ranged from very small to hand-sized examples, and this is probably representative of the range of flint nodules exploited at East Barns during the Mesolithic. It is likely that the nodules recovered from the assemblage were gathered during general collections of raw materials, possibly as part of the daily round, in which selection criteria such as size were low. These pieces were then later examined and tested before being discarded as unsuitable for further working.

Sixteen split flint pebbles were also retrieved; these pieces represent the opening of rounded pebbles/ nodules on an anvil using a direct hard-hammer technique (see below). The mean length of $33.4 \mathrm{~mm}$ given by these pieces appears to reinforce the general small size of the flint available within the locale. However, the subsequent lack of reduction suggests that these too were abandoned due to lack of size.
Those pieces made on chert and chalcedonies were also generally small in size. These pieces gave a mean weight of $9.2 \mathrm{~g}$ and a mean size of $24.7 \mathrm{~mm}$ $\times 21.2 \mathrm{~mm} \times 14.4 \mathrm{~mm}$ and $24.7 \mathrm{~mm} \times 18.1 \mathrm{~mm} \times$ $16 \mathrm{~mm}$ respectively. These sizes compare favourably with nodules recovered from the plough-soil within the vicinity.

A far greater proportion of quartz pebbles $(0.02 \% / 9)$, tested pieces $(0.07 \% / 21)$ and split pebbles $(0.14 \% / 43)$ were recovered from the assemblage than from the other raw materials. This undoubtedly reflects the prevalence of this material within the local till soils. In addition, a single pebble and three split pebbles of quartzite were also recovered. The quartz and quartzite exhibited a far greater size and weight range. However, the mean recorded size and weight was only slightly larger than those of the other raw materials. The quartz pebbles produced a mean size of $39.5 \mathrm{~mm} \times 33.9 \mathrm{~mm} \times 25.4 \mathrm{~mm}$.

The high proportion of split pebbles reflects the use of bipolar knapping as the favoured technique for working this material.

\subsubsection{Cores (Tables 4a, 4b and 4c)}

A total of 518 cores and core fragments were recovered. These occurred in all of the main raw materials (Table 2), with those in flint being the most numerous ( $n$ 390), followed by chert ( $n 63)$, quartz ( $n$ 53) and chalcedony ( $n$ 11). A single quartzite example was also retrieved.

Blade, flake and non-specific platform cores dominate the flint, chert and chalcedony components, followed by smaller numbers of bipolar and amorphous flake types. This is reversed in quartz, where the more intractable nature of the material means that the bipolar technique is more frequently utilised (Table 3).

The general characteristics of each core were recorded including dimensions, weight, number of platforms and extent of working. This information is summarised in Tables $4 \mathrm{a}, 4 \mathrm{~b}, 4 \mathrm{c}$ and 5 .

As the material from the infilling of the structure was possibly contaminated with material from other periods, a more detailed technological analysis was restricted to the 96 cores recovered from the in situ Mesolithic occupation horizons (Contexts 2549, 2561, 2564 and 2573) surrounding the structure. The attributes, stages and dimensions of this sample 
Table 4a Platform core types

\begin{tabular}{lcccccccc} 
Material & \multicolumn{8}{c}{ Platform type } \\
& Single & Opposed & Multi (3) & Multi (4) & Multi (5) & Fragment & Carinated & Totals \\
Flint & 196 & 73 & 30 & 6 & 1 & 19 & 11 & 336 \\
Chert & 36 & 7 & 4 & 2 & 0 & 2 & 0 & 51 \\
Chalcedony & 5 & 5 & 0 & 0 & 0 & 0 & 0 & 10 \\
Quartz & 20 & 1 & 0 & 0 & 0 & 0 & 0 & 21 \\
Quartzite & 0 & 0 & 0 & 0 & 0 & 1 & 0 & 1
\end{tabular}

Table 4b Median core dimensions

\begin{tabular}{lrrr} 
Material & \multicolumn{3}{c}{ Core type } \\
& \multicolumn{1}{c}{ Platform } & \multicolumn{1}{c}{ Bipolar } & \multicolumn{1}{c}{ Amorphous } \\
Flint & $23.93 / 21.4 / 15.51$ & $23.3 / 13.47 / 9.61$ & $23.3 / 21.5 / 16.9$ \\
\hline Chert & $25.0 / 23.61 / 19.5$ & $26.9 / 14.7 / 9.95$ & $30.9 / 28.86 / 21.74$ \\
\hline Chalcedony & $26.96 / 25.11 / 16.6$ & 0 & 0 \\
\hline Quartz & $24.4 / 27.9 / 21.4$ & $20.8 / 13.2 / 7.9$ & 0
\end{tabular}

Table 4c Median core weights

\begin{tabular}{lccc} 
Material & & Core type & \\
& Platform & Bipolar & Amorphous \\
Flint $(n)$ & 9.54 & 3.66 & 10.74 \\
\hline Chert $(n)$ & 17.09 & 4.01 & 30.22 \\
\hline Chalcedony $(n)$ & 23.84 & 13.90 & 0.00 \\
\hline Quartz $(n)$ & 26.70 & 4.75 & $178.44(1)$
\end{tabular}

are given in Tables 6a-6e. This sample was also taken in order to maximise evidence for spatial patterning. A selection of core types is illustrated in Illus 10 .

The distribution of core types is described and discussed in Section 4.6 below, Spatial analysis and material distributions.

\section{General character}

Most of the cores are assumed to have been produced on split or quartered nodules opened through the use of a hard hammer and anvil. Nevertheless, there are examples of platform cores also utilising the flat inner surface of thick primary flakes.
Single platform cores dominate in all raw materials with the exception of chalcedony (Table 4a). Flint provided 196 single platform cores, and a further 73 dual platforms. The majority of these were opposed in form. Multi-stage cores account for 37 pieces, including 30 triple-stage, six four-stage cores and a single five-stage example. This is repeated to a lesser degree in chert, where four triple-stage and two four-stage cores were recorded in a total of 49 whole examples. Chalcedony provided 10 complete cores, equally split between single and dual platform types. Finally, quartz presented 20 single platform cores and one dual platform example. 


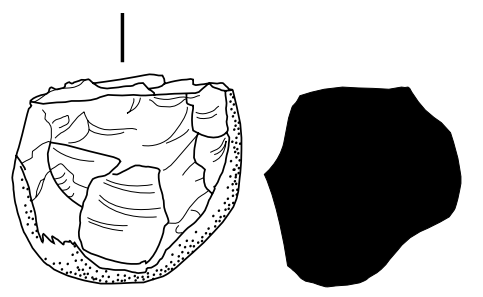

SF6753

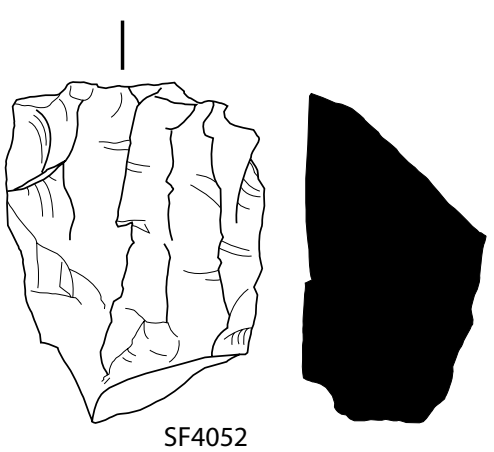

SF4052

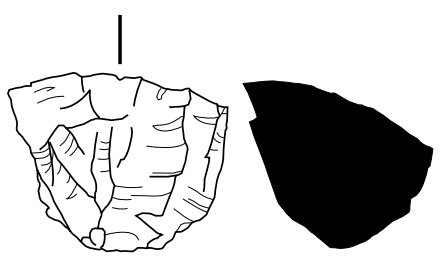

SF8718

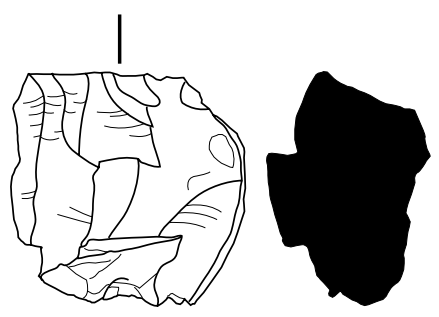

SF9325

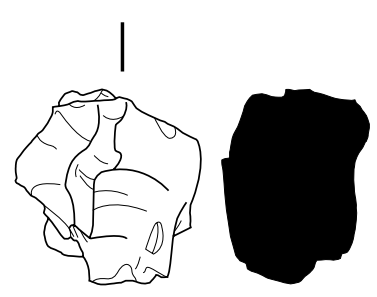

SF9371

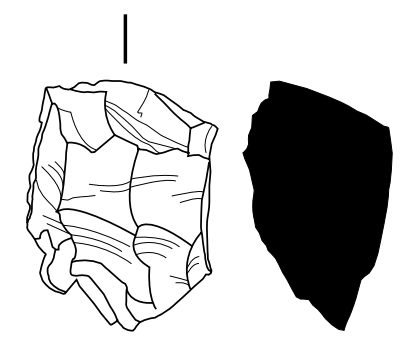

SF9314

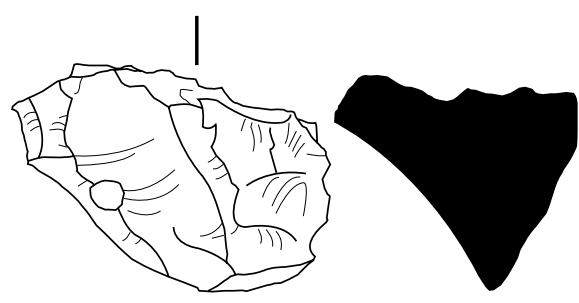

SF9317
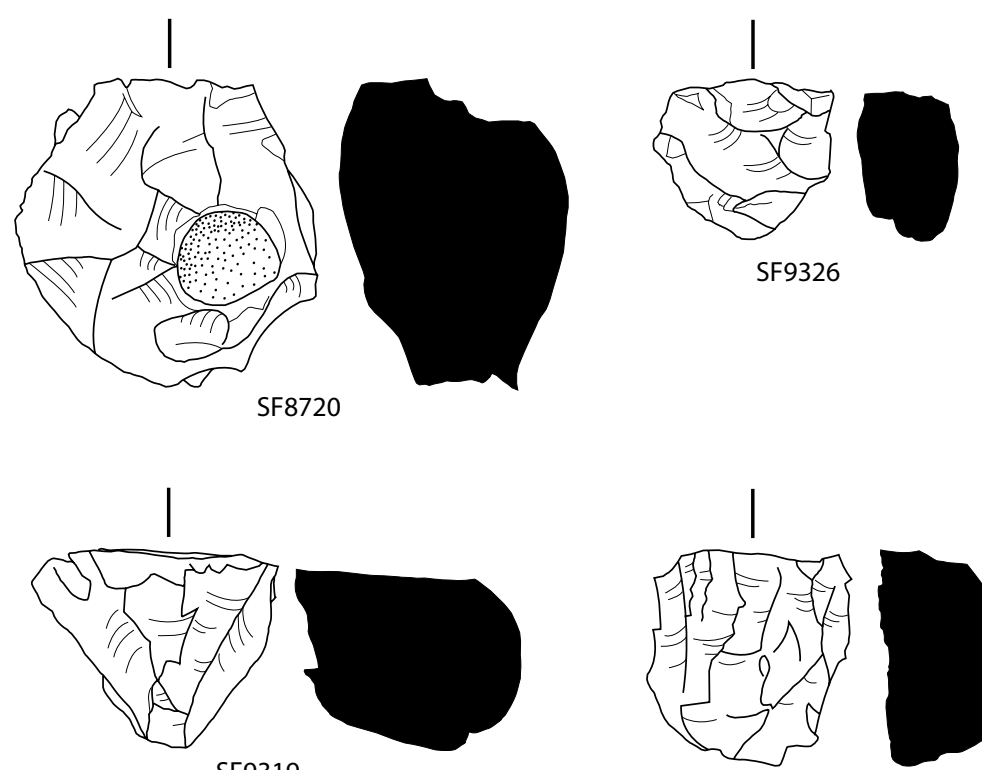

SF9319

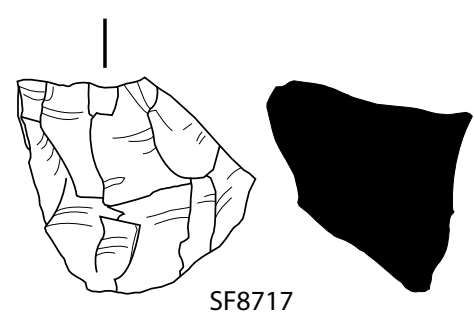

SF8717

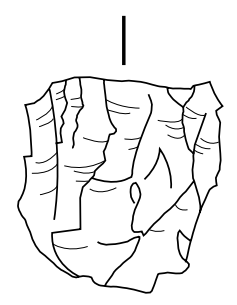

SF9319
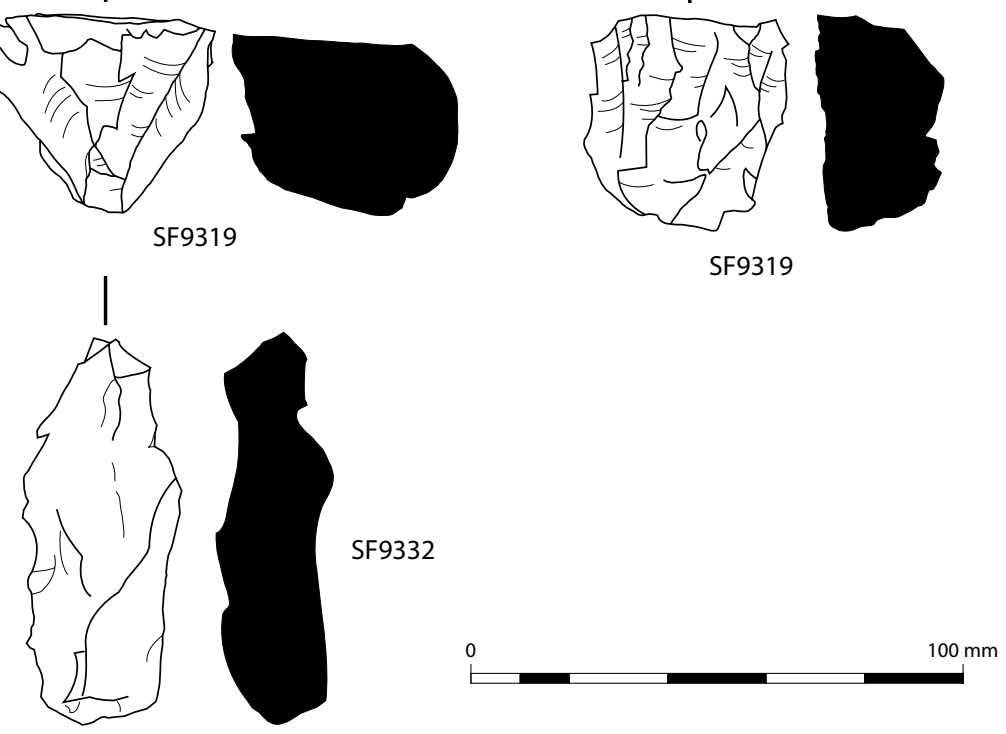

Illus 10 Platform cores and bipolar cores (SF 9371 and SF 9332) (flint unless otherwise indicated) 
Bipolar worked cores were the second most numerous core type (Table 3 ), producing 42 examples in flint and 30 in quartz. Others were also made on chert $(n 7)$ and chalcedony $(n 1)$. The majority of these cores show the characteristic signatures of this reduction technique, including scalar flake removals from both ends of the nodule and crushed impact scars (Illus 10 - SF 9371). The cores included classic thin residual types (Illus $10-$ SF 9332) with scalar scars and less regular, unifacial and bifacial examples. It is likely that the majority of the bipolar cores made on both flint and chert were the result of a deliberate decision to further extend the productivity of platform cores (see below).

Many platform cores exhibit signs of damage consistent with reduction on an anvil. This damage did not seem to produce any sizeable flakes, and this suggests that these are possibly residual marks in many cases, derived from an initial opening or striking of the nodule on an anvil.

Seventeen amorphous cores are recorded within the assemblage, 11 on flint, five on chert and a single example on quartz. Amorphous cores reflect an ad hoc and uncontrolled knapping strategy designed to produce flakes from any suitably sized pieces.

The general dimensions and weights of all 516 cores within the assemblage were recorded. This illustrated that those platform cores made of flint were the smallest in both dimensions and weight (Tables 4a and 4b) and were therefore likely to have been the most heavily worked. This was illustrated by work on the core sample derived from the in situ occupation deposits discussed below. Chert cores were next in size, followed by chalcedony and quartz. Amorphous cores in all materials were the largest, again reflecting the ad hoc nature of their reduction.
Bipolar worked cores were the smallest by weight. However, their mean lengths were consistent with those given by both the platform cores in both flint and chert. This perhaps illustrates that these pieces were initially platform cores, whose utility was extended by the subsequent use of the bipolar technique. Bipolar reduction would provide flakes from both ends of the core but would leave the length of the piece relatively unaltered. Three platform examples (two in flint and one in chert), showed visible evidence of being reworked by the bipolar technique. The smallest bipolar examples in both weight and dimensions were made on quartz. This suggests that bipolar reduction was the primary reduction technique used to work this material at East Barns.

The percentage of worked platform area (Table 5) shows a similar pattern of usage. This again shows flint as being the most intensively worked material, with 87 out of 269 examples revealing a worked platform of over $75 \%$. The 37 flint cores with a completely worked platform include 11 very small carinated examples. The majority ( $n$ 148) were worked at around 50\% with a further 34 worked at $25 \%$ and under.

Of the total 390 flint cores, 80 were in a fresh condition with 107 showing some signs of patination and a further 116 appearing heat affected. A further 72 had significant cortex present showing a smooth, rolled appearance.

\section{Core sample (n 95)}

Of the 95 cores recovered from the in situ Mesolithic occupation deposits, 81 were made on flint with a further nine on chert, three on chalcedony and two on quartz (Table 6a). Blade platform types predominate ( $n 38)$, with the majority being either

Table 5 Platform cores as percentile of worked platform

\begin{tabular}{lcccc} 
Material & \multicolumn{5}{c}{ Platform type } \\
$\%$ area worked & $25 \%$ & $50 \%$ & $75 \%$ & $100 \%$ \\
Flint & 34 & 148 & 50 & 37 \\
\hline Chert & 6 & 20 & 10 & 7 \\
\hline Chalcedony & 3 & 4 & 0 & 3 \\
\hline Quartz & 4 & 11 & 2 & 3 \\
\hline Quartzite & 0 & 0 & 0 & 0
\end{tabular}


Table 6a Selected occupation deposits: core attributes

\begin{tabular}{|c|c|c|c|c|}
\hline Probable reasons for abandonment & Flint & Chert & Chalcedony & Quartz \\
\hline Indeterminate & 2 & 0 & 0 & 0 \\
\hline Size & 46 & 3 & 3 & 2 \\
\hline Flaws & 7 & 2 & 0 & 0 \\
\hline Overshot & 1 & 0 & 0 & 0 \\
\hline Stepping/hinging & 17 & 4 & 0 & 0 \\
\hline Angle & 1 & 0 & 0 & 0 \\
\hline Stepping/hinging and angle & 7 & 0 & 0 & 0 \\
\hline \multicolumn{5}{|l|}{ Cortex type } \\
\hline None & 27 & 1 & 0 & 2 \\
\hline Smooth/chalky & 4 & 0 & 0 & 0 \\
\hline Smooth/hard & 37 & 6 & 2 & 0 \\
\hline Pitted & 9 & 2 & 0 & 0 \\
\hline Battered & 4 & 0 & 1 & 0 \\
\hline \multicolumn{5}{|l|}{ Estimate of pebble size } \\
\hline Indeterminate & 34 & 1 & 0 & 0 \\
\hline Small & 44 & 7 & 2 & 2 \\
\hline Medium & 3 & 1 & 1 & 0 \\
\hline Large & 0 & 0 & 0 & 0 \\
\hline \multicolumn{5}{|l|}{ Angularity/sphericity } \\
\hline Indeterminate & 43 & 1 & 0 & 2 \\
\hline Angular (nodular) & 13 & 7 & 1 & 0 \\
\hline Sub-angular & 17 & 1 & 2 & 0 \\
\hline Sub-rounded & 6 & 0 & 0 & 0 \\
\hline Rounded & 2 & 0 & 0 & 0 \\
\hline \multicolumn{5}{|l|}{$\%$ of platform area } \\
\hline$<$ or $c .25 \%$ & 17 & 2 & 1 & 2 \\
\hline$<$ or c. $50 \%$ & 36 & 6 & 2 & 0 \\
\hline < or c. $75 \%$ & 20 & 1 & 0 & 0 \\
\hline$<$ or c. $100 \%$ & 8 & 0 & 0 & 0 \\
\hline
\end{tabular}


Table 6b Selected occupation deposits: core stage attributes

\begin{tabular}{|c|c|c|c|c|}
\hline Type & Flint & Chert & Chalcedony & Quartz \\
\hline Bipolar & 10 & 0 & 0 & 2 \\
\hline Blade platform & 35 & 2 & 1 & 0 \\
\hline Flake platform & 16 & 3 & 2 & 0 \\
\hline Non-specific platform & 19 & 4 & 0 & 0 \\
\hline Amorphous & 1 & 1 & 0 & 0 \\
\hline \multicolumn{5}{|l|}{ Platform type } \\
\hline Unprepared & 16 & 0 & 0 & 2 \\
\hline Simple preparation & 65 & 9 & 3 & 0 \\
\hline Complex preparation & 0 & 0 & 0 & 0 \\
\hline Lost & 0 & 0 & 0 & 0 \\
\hline \multicolumn{5}{|l|}{ Predominant removal } \\
\hline Indeterminate & 13 & 1 & 0 & 0 \\
\hline Flake & 21 & 4 & 2 & 2 \\
\hline Blade & 35 & 1 & 1 & 0 \\
\hline Mixed & 12 & 3 & 0 & 0 \\
\hline \multicolumn{5}{|l|}{ Negative bulb } \\
\hline Not present & 27 & 2 & 2 & 0 \\
\hline Marked & 44 & 4 & 1 & 0 \\
\hline Diffuse & 10 & 3 & 0 & 0 \\
\hline \multicolumn{5}{|c|}{ Flake/blade scar dimensions } \\
\hline Mean length & 21.81 & 17.11 & 17.36 & 0 \\
\hline \multicolumn{5}{|c|}{ Standard deviation length } \\
\hline Maximum length & 39.7 & 26.5 & 20.2 & 0 \\
\hline Minimum length & 5.6 & 7.5 & 15.5 & 0 \\
\hline \multicolumn{5}{|l|}{ Mode length } \\
\hline Mean width & 9.69 & 9.82 & 9.13 & 0 \\
\hline \multicolumn{5}{|l|}{ Standard deviation width } \\
\hline Maximum width & 19.8 & 16.3 & 12.2 & 0 \\
\hline Minimum width & 3 & 5.3 & 4.2 & 0 \\
\hline
\end{tabular}


Table 6c Selected occupation deposits: platform type by stage

\begin{tabular}{lcccccc} 
& Stage 0 & Stage 1 & Stage 2 & Stage 3 & Stage 4 & Stage 5 \\
Bipolar & 0 & 15 & 0 & 0 & 0 & 0 \\
\hline Blade platform & 14 & 1 & 14 & 6 & 3 & 0 \\
\hline Flake platform & 8 & 0 & 9 & 3 & 0 & 1 \\
\hline Non-specific platform & 5 & 0 & 13 & 5 & 1 & 0 \\
\hline Amorphous & 0 & 2 & 0 & 0 & 0 & 0
\end{tabular}

Table 6d Selected occupation deposits: bipolar core dimensions

\begin{tabular}{lcccc} 
& \multicolumn{4}{c}{ Bipolar } \\
& Length & Width & Thickness & Weight \\
Mean & 23.15 & 13.25 & 8.3 & 2.92 \\
\hline St. Dev. & & & & \\
\hline Max. & 40 & 18.5 & 12.4 & 5.47 \\
\hline Min. & 17.2 & 7.7 & 4.2 & 1.18
\end{tabular}

single stage ( $n$ 14) or dual stage ( $n$ 14). A further nine are recorded as multi-stage pieces (Table 6c). The blade platform cores range in form from classic conical examples to more simple types with limited removals. Non-specific platforms (NSP) (n 24) and flake platforms $(n 21)$ follow. The majority of NSP cores are double ( $n$ 13) or multi-stage ( $n$ 6). Only five of this core type was single-stage. NSP cores therefore would appear to represent a strategy employed to extend the utility of the core through a change in emphasis from blade production to the less restrictive creation of serviceable flakes. Flake platform cores provide eight single stages, nine opposed and four multi-stage examples, one of which has five stages. Twelve bipolar cores and two amorphous flake cores were also recorded all on flint, with the exception of two bipolar cores made on quartz and one amorphous core on chert. It is suggested that bipolar reduction was used to both extend core utility in flint and to more successfully utilise the more intractable quartz component of the assemblage.

As with the data garnered from the general core assemblage (Table 5), the majority of the sample had a worked platform area of approximately 50\% (n 44). A further 21 were worked around 75\% and eight were completely worked. Twenty-two cores were worked at 25\% and less (Table 6a). This suggests that cores were often not worked to exhaustion but may have been abandoned for a variety of other reasons, such as internal flaws.

The evidence from the core sample would suggest that the majority of the parent nodules were relatively small in size ( $n$ 55). Bipolar cores were the smallest of the core types, given that the majority of these represent the final stage of platform worked cores (Table 4a). Of the platform types, single-stage cores had both the smallest average dimensions and weight followed by opposed and multi-stage types (Table $4 b)$. Though the differences are not great, it would suggest that the larger of the collected nodules were the most intensively worked. Nevertheless, only five cores were judged as coming from medium-sized nodules and the average size of the raw material appeared generally small.

The suggested shape of these nodules was angular (nodular) ( $n 21)$ or sub-angular ( $n$ 20) with only six sub-rounded and two rounded. Forty-six pieces were recorded as indeterminate (Table 6a).

Sixty-five of the cores had visible cortex (Illus 10 - SF 6753), unsurprising given the general size and proposed angularity of the parent nodules. The 


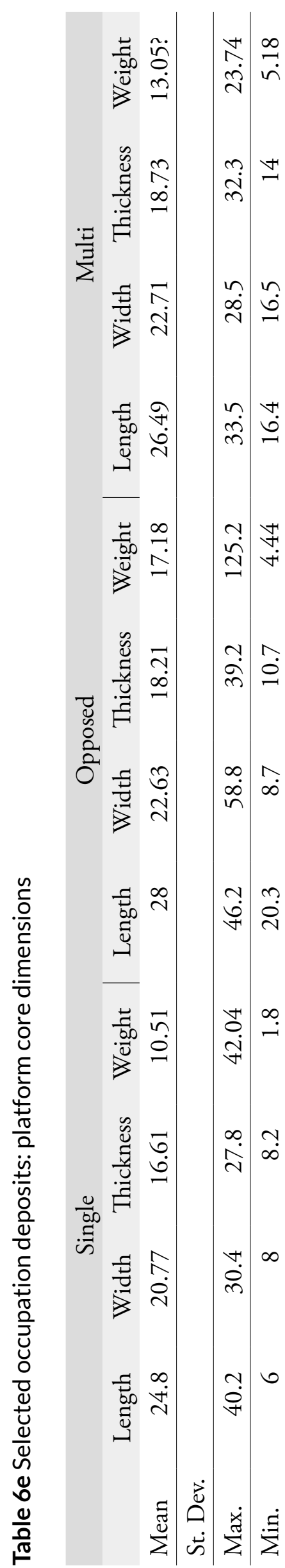

cortex was smooth, hard and water-rolled on 45 examples. Four presented a similarly smooth yet soft and chalky cortex. A further 11 had the pitted cortex characteristic of a nodular, glacial origin. Five were battered in appearance (see Section 4.2, Lithic raw materials).

The apparent small size of the raw material was probably a major restriction to reduction. In estimating the most probable reason for the abandonment of the cores, size was the most frequent, accounting for 54 of the pieces (Table 6a). This was followed by stepping/ hinging ( $n 21)$, inherent flaws within the material ( $n$ $9)$ and stepping/hinging and angle $(n 7)$. A single core was overshot. In two examples the cause was considered indeterminate.

Preparation of the core platforms appears to have been restricted to the simple trimming of the platform edge in order to remove spurs and overhangs caused by previous removals (Table 6b). Platforms are largely restricted to the utilisation of a flat surface produced through the initial splitting or flaking of a nodule. This was noted on 77 of the cores, with a further 18 relying simply on the cortical surface of the nodule itself.

The most frequent removal is that of blades ( $n$ 37) followed by flakes ( $n$ 29) and then mixed blades/flakes ( $n$ 15). A further 14 are indeterminate. It is noted that both regular and more scalar type flake removals are present especially on those cores with more than a single stage. These scalar type removals may reflect the working of the core on an anvil.

Negative bulbs present on the cores are largely marked ( $n$ 49), with only 13 being recognised as diffuse.

The average measurable length of removals is $21.81 \mathrm{~mm}$ for flint blade/flake scars. Both chert and chalcedony are smaller, at $17.00 \mathrm{~mm}$ and $17.36 \mathrm{~mm}$ respectively.

\section{Nodules, split nodules and tested pieces}

The evidence from the pebble, core and blank analyses undertaken at East Barns suggests that the assemblage is derived from the working of relatively small, locally available, nodular raw materials. The reduction of these materials is visibly hierarchical in form. Flint is the most numerous and most intensively worked raw material, followed by chert, quartz and chalcedony. 
The pebbles and tested pieces recovered from the excavation are not numerous and can be defined by their small size. In many cases the given dimensions are smaller than those of the cores within the assemblage and suggest that these pieces represent material initially brought onto site and later rejected as either too small or flawed for further reduction.

\section{Core reduction}

The high frequency and technological attributes of both cores and core-related debitage suggest that the primary reduction of all raw materials was undertaken on site through a variety of techniques, with the majority worked from platforms. Most of these platforms consisted of the flat surfaces created by the splitting of nodules with the implied use of an anvil.

Though the platform working of cores is dominant in all materials with the exception of quartz, there is distinct variability within the primary technology of the assemblage. This is illustrated by the significant presence of the bipolar technique and more amorphous flake core types. It is probable that the relationship between the identified range of reduction strategies is more complicated than is suggested in this report. A high degree of flexibility was probably employed, in order to maximise the productivity of the small nodular material.

The bipolar technique was used to extend the productive life of both the flint and chert cores and appears to have often been the final recognisable stage of core reduction. Although quartz is also capable of producing platform cores, it was more often worked through the bipolar technique. This technique is often used in connection with the working of more intractable raw materials.

\section{Core rejuvenation}

A variety of rejuvenation strategies were employed in order to maintain both core face and platform utility. These included platform rejuvenation flakes struck from the side, core-trimming flakes and coretrimming flakes which also removed the existing platform. The latter two examples were struck to remove stacked steps which occurred at the platform edge or core face as a result of inherent flaws within the raw material or knapping errors.
The presence of platform rejuvenation and coretrimming flakes confirms the importance of platform reduction within the assemblage and emphasises that the size of the nodules did not inhibit the rejuvenation of the cores. It suggests that perhaps larger nodules were exploited than is immediately apparent from either the cores or pebbles recovered from the excavation.

\section{Core stages}

The number of stages produced by the analysis of the core sample obtained from the selected Mesolithic occupation deposits shows that a significant proportion of the cores were intensively worked. Single stage flint cores were the smallest of the platform types in both dimensions and weight, suggesting that initially larger and higher quality pieces were more intensively worked.

\section{Platform area}

The intensity of reduction was also visible in the amount of work to which the perimeter of the core had been subjected. At East Barns a study of the overall number of platform cores of all raw materials within the assemblage showed the majority were worked at around 50\% (53.50\%), with $18.1 \%$ worked at $75 \%$ and $14.6 \%$ being completely worked. These figures are replicated in the sample taken from the Mesolithic occupation deposits and suggest that the cores at East Barns were fairly intensively worked.

\section{Core abandonment}

The core sub-sample from the Mesolithic occupation deposits showed size was the most common reason for core abandonment, followed by technical problems such as stepping, hinging and angle and internal flaws. In experimental work undertaken by master flint knapper John Lord on beach pebbles from the SHMP (Mithen et al 2000: 531) size was shown to be the main reason for the abandonment of blade cores derived from a beach pebble source.

\subsubsection{Chunks}

Chunks account for 6.6\% ( $n$ 1,987) of the assemblage. The majority of these are made on flint $(n 1,215)$ with smaller numbers of chert $(n 398)$, quartz ( $n$ 324), chalcedony ( $n$ 40) and quartzite $(n$ 
10). $41.54 \%$ ( $n 806)$ of the chunks showed evidence of burning with a further 226 showing some degree of patination.

\subsubsection{Fragments}

A total of 132 fragments were recovered, nine of flint, 120 of quartz and three of chert. These differ from the chunk category in form because they have a particularly 'orange segment' appearance. This is often coupled with signs of percussion impact. It is probable that these pieces represent waste material from bipolar reduction.

\subsubsection{Flakes (Table 3)}

Flakes account for $28.45 \%$ of the assemblage: $23 \%(n 7,050)$ are flint, 3.2\% ( $n$ 973) chert, $0.49 \%$ ( $n$ 147) chalcedony, $1.3 \%$ ( $n$ 383) quartz and $0.1 \%(n 23)$ quartzite; $9.9 \%(n$ 852) of the flake total are primary removals with $21.6 \%(n$ $1,854)$ secondary and $68.3 \%$ ( $n 5,854)$ tertiary. Of the flint flakes, 1,832 were patinated and 2,672 burnt.

Regular flakes account for 32.1\% ( $n 2,752)$ of the flake total, with irregular examples at $63.8 \%$ (n 5,471).

Edge damage commensurate with use-wear is considered to have affected 152 flakes. A sample of these flakes from the occupation deposits was submitted for use-wear analysis (see Section 5, Lithic microwear analysis). It is recognised that some edge damage may also be the result of post-depositional factors such as trample.

Twenty-two bipolar/scalar flakes were recognised within the assemblage. These pieces have the characteristic opposed crushed striking platforms and percussion features associated with this technique. Given the presence of other debitage classes with bipolar characteristics such as cores, 'orange segment' fragments and split pebbles within the assemblage, it is likely that these flakes represent only a small fraction of the true total.

A total of 316 flake fragments were recorded which have neither recognisable proximal nor distal ends.

Fifteen spalls were also recognised. As with the bipolar flakes, the identification of these pieces was restricted to those examples with an easily recognisable form.

\section{Rejuvenation strategies}

A total of 302 ( $1 \%$ of the assemblage) rejuvenation flakes were recovered during the excavation. Of these 138 (45.7\%) were retrieved from the infilling deposits of the house. The majority were made on flint, although they occur in all four of the main raw materials (Table 3). A number of rejuvenation flakes have been modified, and appear in the catalogue under various categories.

The majority of the flakes ( $n$ 243) appear to have been removed in order to eliminate stacked steps, flaws, uneven platform surfaces and overhangs from the existing platform area. Most are fairly regular in form and have been struck from the side at a $90^{\circ}$ angle to the platform edge. In all cases these appear to have been struck from simple, flat surface platforms and with the exception of two examples which also remove opposing platforms, appear unidirectional. No true crested blades were identified within the assemblage.

Fifty-seven rejuvenation flakes appeared to trim or remove the core face. The majority of these were designed to remove step fractures and spurs. However, some do appear deliberately overshot, possibly in order to re-shape the core face. This number is undoubtedly on the low side as there is some degree of difficulty in isolating such flakes from more general removals.

\subsubsection{Blades (Table 3)}

The term 'blade' adheres rigidly to the description given in the 1999 edition of the Technology and terminology of knapped stone (Inizan et al 1999: 71). The overall lamellar index for the assemblage is $15.8 \%$.

Blades account for $4.5 \%$ of the assemblage: $3.9 \%$ are flint, with $0.5 \%$ chert and $0.1 \%$ chalcedony; $3.8 \%$ are tertiary with $0.7 \%$ secondary and only five considered primary removals.

$1.5 \%$ of the blades are patinated, with $0.6 \%$ burnt or heat affected, $2.3 \%$ considered fresh, $0.02 \%$ pitted and $0.13 \%$ rolled.

$0.3 \%$ were considered edge damaged as a likely result of use or post-depositional trample. As with the flakes, a sample was submitted for use-wear analysis (see Section 5, Lithic microwear analysis). 


\subsubsection{Flake/blade technological analysis (Tables} $7 a-d)$

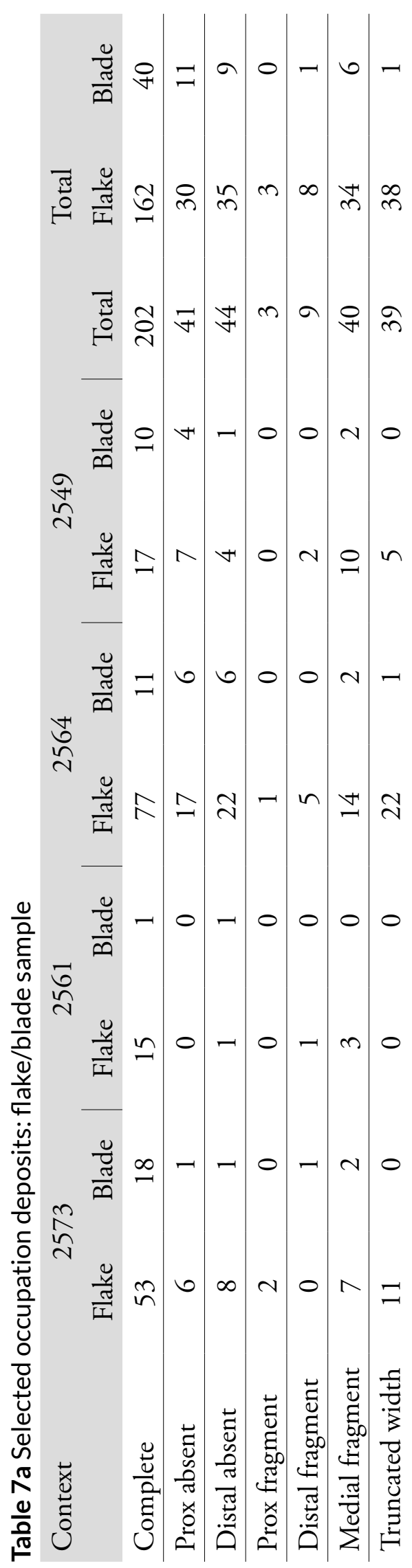

A technological analysis was conducted on a sample of 378 pieces ( $n 310$ flakes and 68 blades) retrieved from randomly selected quadrate squares within the in situ Mesolithic occupation deposits surrounding the house (Contexts 2549, 2561, 2564 and 2573). These quadrates were associated with the same deposits that produced both the core and fine fraction analyses. The profile of the sample pieces is given by context in Table 7 .

Fragmentary pieces account for $46.6 \%$ of the sample. These are almost equally divided between absent distal and proximal ends ( $n 44$ and 41 respectively), medial fragments $(n 40)$ and pieces with truncated widths ( $n$ 39).

The sample comprised $94.2 \%$ flint, with $4.8 \%$ chert and relatively insignificant numbers of quartz, chalcedony and quartzite. Of the combined sample, $33.6 \%$ showed signs of burning. The lamellar index for the sample as a whole is 19.10 . By context the index is as follows: Context $2549=37.7$, Context $2561=10$, Context $2564=16.45$ and Context $2573=26.4$.

The sample produced 202 complete pieces, the dimensions and technological attributes of which are given in Tables $7 \mathrm{~b}-\mathrm{c}$.

118 of the pieces were tertiary, with cortex located in small numbers on both proximal and distal ends (Table 7b). The lateralisation of cortex is also restricted in number, with left-hand side (LHS) (n 14) cortical pieces slightly outnumbering right-hand side (RHS) ( $n$ 6). Pieces with cortex visible in combination are the second most numerous category $(n 50)$.

Diffuse bulbs of percussion ( $n$ 115) are the most common bulb type within the sample, followed by pronounced examples $(n 69)$.

$46.5 \%$ of the platforms are simply prepared, with cortical platforms accounting for $11.9 \%$ and crushed platforms $28 \% .11 .9 \%$ were absent or indeterminate with three appearing faceted.

Jagged/irregular distal terminations are the most frequently occurring, with $33 \%$ with abrupt next at $27 \%$, feathered $13.9 \%$ ( $n$ 28), hinge 13.4 ( $n$ 27) and plunging 11.4 ( $n$ 23) terminations follow in relatively similar amounts.

With the exception of numerical differences, the composition and character of the four contexts represented in the sample show only slight differences in the attribute profile. Contexts 2564 and 2573 


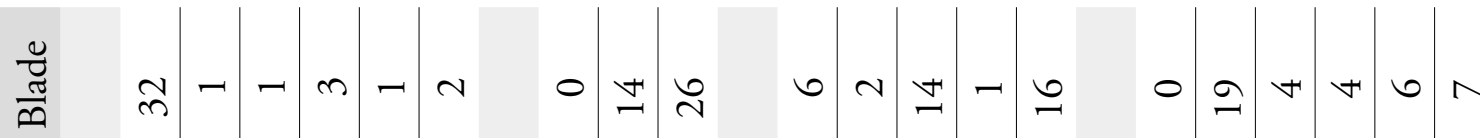

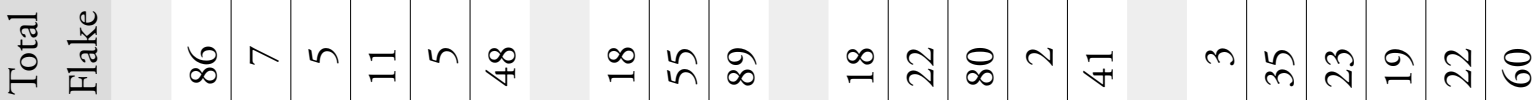

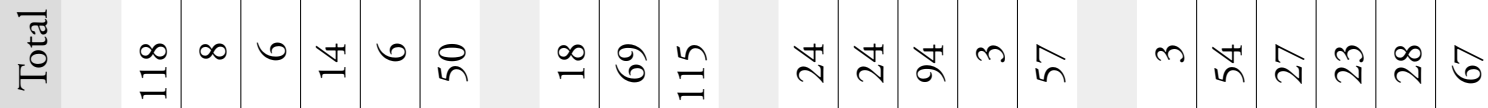

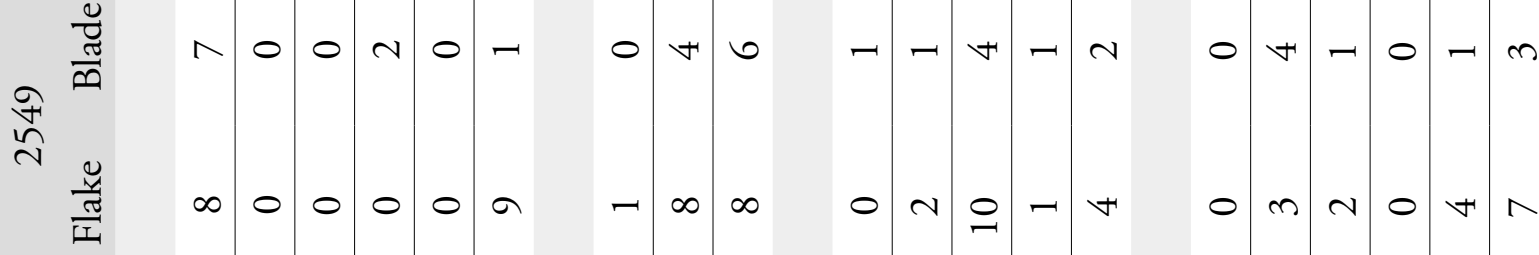

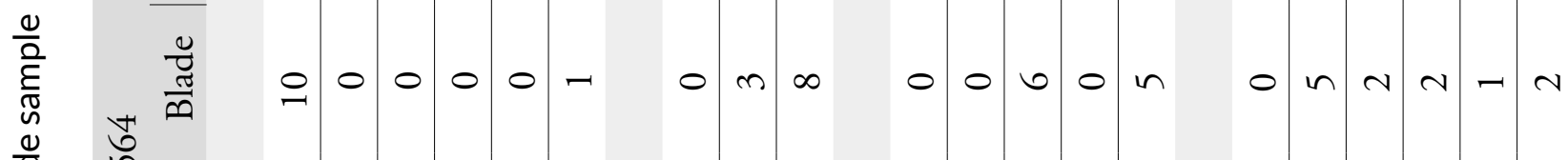

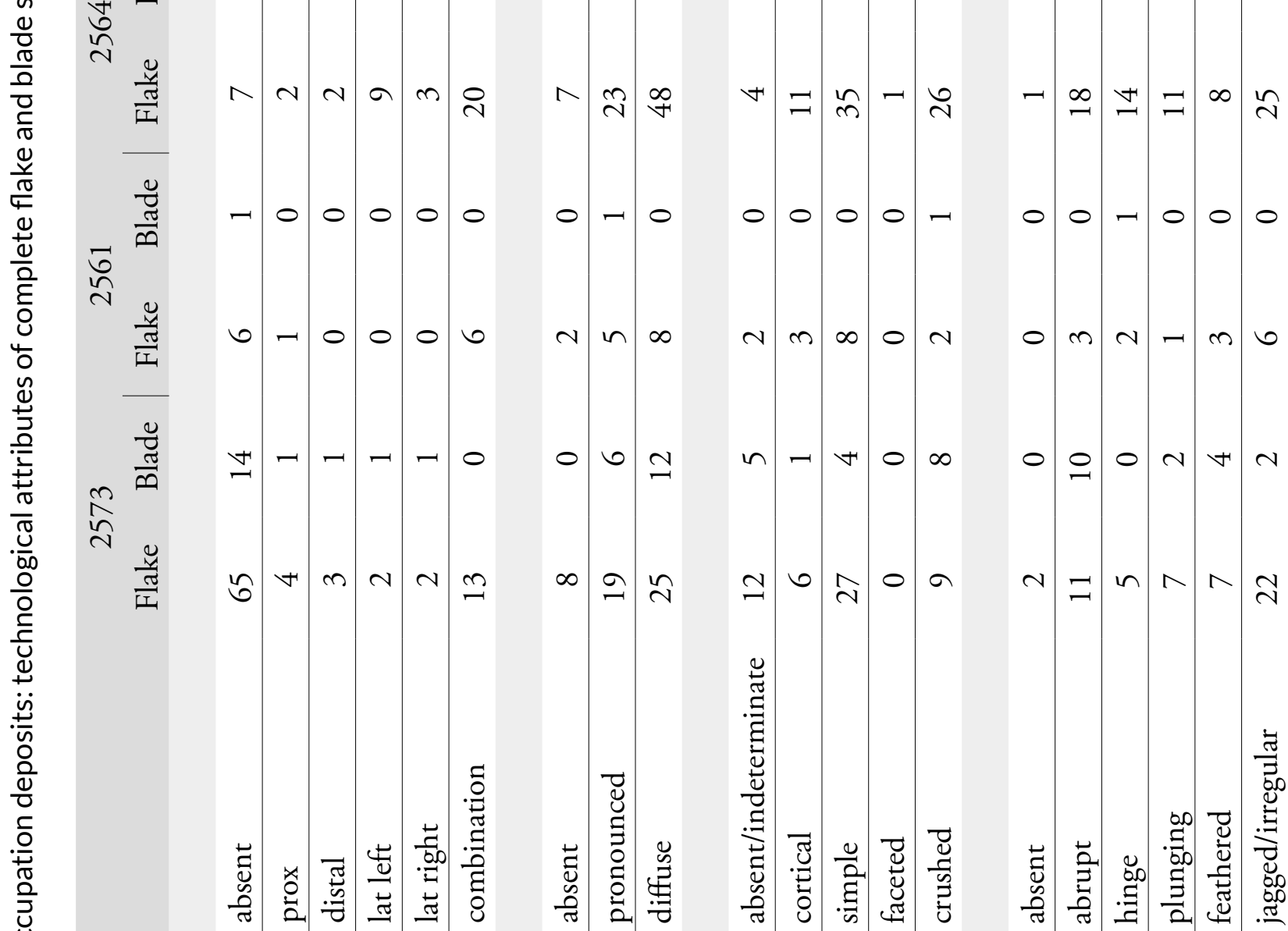

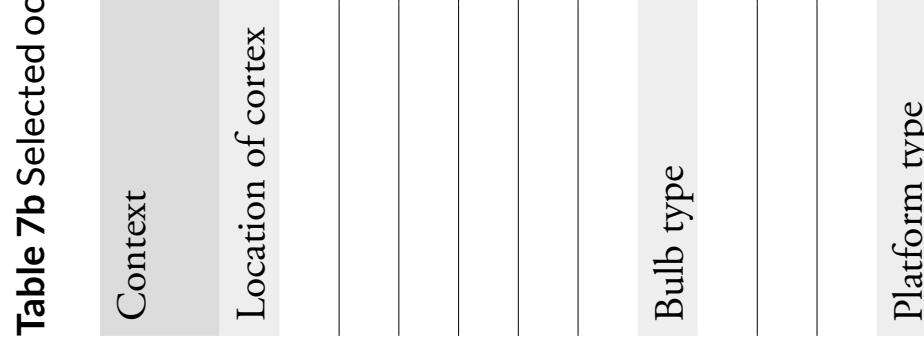

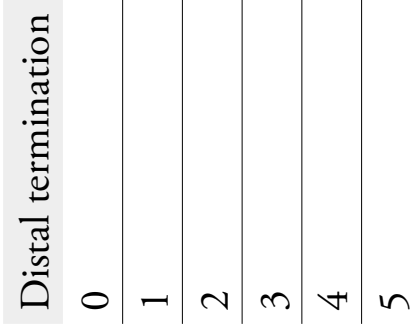


Table 7c Selected occupation deposits: complete flake dimensions

\begin{tabular}{lrrc} 
& Length & Width & Thickness \\
Mean & 18.34 & 12.64 & 3.71 \\
\hline St. Dev. & & & \\
\hline Max. & 48 & 35 & 14 \\
\hline Min. & 9 & 5 & 1
\end{tabular}

Table 7d Selected occupation deposits: complete blade dimensions

\begin{tabular}{lccc} 
& Length & Width & Thickness \\
Mean & 22.6 & 9.16 & 2.74 \\
\hline St. Dev. & & & \\
\hline Max. & 51 & 23 & 6 \\
\hline Min. & 13 & 4 & 1
\end{tabular}

provide $77.8 \%$ of the sample and suggest more intensive areas of working/dumping. Context 2573 has 39\% of all tertiary material, with Context 2564 having a slightly greater proportion of cortical material. Blades are fairly equally distributed across Contexts 2564, 2573 and 2549, with the latter having a particularly high lamellar index (37.7).

\subsubsection{Fine fraction}

Fine fraction debitage accounts for $53 \%$ of the chipped stone assemblage. Again, most of the material is made on flint ( $n$ 14,433), with smaller amounts of chert $(n 765)$, quartz $(n 713)$ and chalcedony ( $n$ 80).

The majority of the fine fraction consists of tertiary material (97.8\%), with 261 secondary and 95 primary pieces.

A sample of the fine fraction debitage was taken from the same quadrate squares as used for the technological analysis of the flake and blade sample. This produced a total of 584 pieces.

\subsubsection{Technological analysis (Tables 8a and 8b)}

Of the 584 pieces retrieved from the technological sample, 568 were of flint. Very small numbers of chert $(n 9)$ and quartz $(n 7)$ were also present. Flakes dominate, constituting $94 \%$ of the sample.
Of these, $85 \%$ are tertiary, with $11.6 \%$ secondary and $3.4 \%$ primary. $54.6 \%$ are complete, with $30.6 \%$ fragmentary and $14.9 \%$ indeterminate. The condition of the fine fraction debitage is predominantly burnt or heat affected $(62.7 \%)$, with $29.7 \%$ appearing fresh and $7.4 \%$ patinated. Only one piece was judged rolled.

\subsubsection{Blades and flakes (Tables 7a-d)}

Despite having an overall lamellar index of only $15.8 \%$, which is well under the total of $20 \%$ proposed by Bordes \& Gaussen (1970) for the definition of a blade technology, the assemblage at East Barns can be comfortably characterised as a 'narrow blade' industry. This approach, in which the quantity of blades in the assemblage is compared to that of flakes, has been criticised as rather mechanical by Ballin (2014: 16). It must therefore be reiterated that the blades within the assemblage were identified by a strict set of criteria and that the study of both blanks and flake scars suggests that a significant proportion of the regular flake assemblage was relatively narrow and bladelike in form. It is also apparent that within the study of the selected in situ Mesolithic occupation deposits, the indices of two contexts (2549 and 2573) both showed a high ratio of blades to flakes (37.7 and 26.4) as well as a matching predominance of platform blade cores. 
Table 8a Selected occupation deposits: fine fraction attributes

\begin{tabular}{llccc} 
Blank & & Flint & Chert & Quartz \\
& Flake & 535 & 9 & 5 \\
\hline \multirow{2}{*}{ Cortex } & Chunk & 33 & 0 & 2 \\
& & & & \\
& Primary & 18 & 0 & 2 \\
\hline \multirow{3}{*}{ Condition } & Secondary & 68 & 0 & 0 \\
\hline \multirow{3}{*}{} & Tertiary & 482 & 9 & 5 \\
\hline & Burnt & 366 & 0 & 0 \\
\hline \multirow{2}{*}{ Fragmentation } & Fresh & 165 & 9 & 0 \\
\hline & Patinated & 36 & 0 & 7 \\
\hline & Rolled & 1 & 0 & 0 \\
\hline & Complete & 308 & 4 & 6 \\
\hline & Fragment & 176 & 2 & 1 \\
\hline & Indeterminate & 84 & 3 & 0
\end{tabular}

Table 8b Selected occupation deposits: fine fraction by context

\begin{tabular}{lrrrrrr} 
Context & 2573 & & 2561 & & 2564 & 2549 \\
Quadrant & G10 & G12 & B6 & A9 & F6 & D15 \\
\hline Total & 54 & 89 & 21 & 69 & 220 & 141
\end{tabular}

The lamellar index was originally created to analyse material from areas rich in high-quality chalk flint. Therefore the small nodular material characteristic of East Barns and most other Mesolithic sites in northern Britain may be seen to have imposed some constraints on the traditional views of blade production (Finlay et al 2000). That blade manufacture was an important focus of the Mesolithic reduction sequence undertaken at East Barns is not in doubt, given the general make-up of the assemblage. However, the high number of flake cores, varied scraper types and other tool forms intentionally created on flakes suggest blade manufacture was not always the primary objective. It is felt important therefore that the blade/flake ratio is used in conjunction with analyses that assess the frequency of blade platform cores within an assemblage to determine the dominance of blade technology.

\section{Blade and flake dimensions}

The dimensions of both the flake and blade blanks suggest that flakes are on average wider and thicker than blades, though the mean length is relatively similar. The blank sizes also display a very similar range of maximum and minimum dimensions, reinforcing this observation.

The mean dimensions of the flake/blade scars occurring in the core sub-sample (Table 6b) are very similar to those taken from the blank analysis, suggesting that the creation of relatively long, narrow regular blanks was the primary manufacturing purpose within the assemblage. This regularity would also seem to reflect a high degree of skill being employed in the knapping carried out at the site. 


\section{Blade and flake fragmentation}

Of the 584 pieces retrieved from the technological sample, 30.6\% were recorded as fragmentary, with $14.9 \%$ indeterminate. No clear pattern emerges as the categories consisting of absent proximal and distal ends, medial fragments and pieces with truncated widths all have similar proportions (Tables $7 \mathrm{c}-\mathrm{d}$ ). The latter are thought to be related to bipolar reduction (Finlayson et al 2000: 563). Given that the pieces occur in both probable dump and working deposits situated around the exterior of the structure (see Section 4.6, Spatial analysis and material distributions), it is likely that a proportion are the result of trample and other post-depositional factors.

\section{Reduction techniques}

The bulb types present on the complete blades and flakes recovered from the in situ occupation deposits were categorised as pronounced or diffuse in order to help determine the dominant percussion technique used within the assemblage. There are 115 pieces with diffuse bulbs followed by 69 with pronounced bulbs. The greater number of diffuse bulbs is present in both flakes and blades although the ratio is greater in the former.

Diffuse bulb types are often seen as indicative of direct soft-hammer percussion, and pronounced bulbs are usually associated with hard-hammer techniques. However, Zetterlund (1990) has queried this relationship, arguing that attributes often thought characteristic of technique may be affected by a range of other factors such as skill, platform size, angle of impact and raw material quality. At Kinloch Farm, Rhum, it was concluded that soft percussion was used, and that this produced a range of attributes normally associated with hard percussion (ibid: 66).

The presence of only three probably accidentally faceted platforms within the sample indicates that careful preparation of the core platform prior to blank removal was not a major consideration of the knappers of East Barns. Within the studied sub-sample, $25.7 \%$ were identified as simple and narrow. A further $15.6 \%$ appeared crushed or collapsed. Narrow platforms suggest that the platform was struck directly and close to the edge, a technique which when slightly misdirected results in a high number of crushed examples. Crushed platforms are a common phenomenon when direct soft percussion is used (Zetterlund 1990: 71). The application of direct soft-hammer percussion is also supported by the high number of marked scars on the core sample.

With regard to blank terminations, jagged/ irregular, abrupt and hinge distal terminations together account for $73.4 \%$ of the sample. This perhaps is a result of the use of small flawed material combined with occasionally poorly controlled direct soft-hammer percussion.

The bipolar flakes and debitage are probably under-represented within the catalogue, given the large amount of recognised cores. Many of the short thick flakes present within the assemblage are probably the result of bipolar application.

The evidence from East Barns would seem to support a similar conclusion to that reached at Kinloch Farm. Direct soft-hammer technique using a variety of differing percussors appears to have been the dominant method of producing blade/flake blanks. However, the significant quantity of bipolarrelated material would suggest that a hard-hammer technique was also important. It is therefore likely that a variety of techniques and percussor types were utilised in the creation of the assemblage.

\subsection{Secondary technology}

\subsubsection{Introduction}

Modified pieces form 3.8\% of the total assemblage, with microliths and scrapers predominating (Table 9). Pieces made on flint dominate, accounting for $86.2 \%$ of the total. Chert provided $10.5 \%$, followed by chalcedony with $2.7 \%$ and quartz at $0.6 \%$.

$28.6 \%$ of the pieces show signs of patination and $20.4 \%$ appear burnt or heat affected to variable degrees. The dimensions and weight of each individual piece were recorded in the main catalogue alongside a brief description. Samples of each artefact category are illustrated in Illus 11-14.

\subsubsection{Microliths}

A total of 407 identifiable and 50 fragmentary geometric, backed and obliquely blunted narrowblade microliths were recovered (Table 10). The complete pieces recovered from the in situ Mesolithic occupation deposits were subjected to a 
Table 9 Secondary technology

\begin{tabular}{lrrrrr} 
& \multicolumn{2}{c}{ Material } & \multicolumn{2}{c}{ Total } \\
Type & Flint & Chert & Chalcedony & Quartz & \\
Microliths & 332 & 64 & 11 & 0 & 407 \\
\hline Microlithic fragments & 47 & 3 & 0 & 0 & 50 \\
\hline Scrapers & 309 & 19 & 8 & 3 & 339 \\
\hline Scraper fragments & 15 & 0 & 1 & 0 & 16 \\
\hline Scraper rejuvenation flakes & 12 & 1 & 0 & 0 & 13 \\
\hline Microburins & 45 & 4 & 1 & 2 & 52 \\
\hline Notch and snaps & 40 & 3 & 1 & 0 & 44 \\
\hline Notched pieces & 43 & 7 & 1 & 1 & 52 \\
\hline Lamelles a cran & 2 & 0 & 0 & 0 & 2 \\
\hline Denticulates & 22 & 0 & 3 & 0 & 25 \\
\hline Possible burins & 15 & 5 & 0 & 0 & 20 \\
\hline Points & 27 & 5 & 3 & 1 & 36 \\
\hline Retouched pieces & 94 & 12 & 2 & 0 & 108 \\
\hline Knives & 2 & 1 & 0 & 0 & 3 \\
\hline Total & 1005 & 124 & 31 & 7 & 1165
\end{tabular}

Table 10 Microliths

\begin{tabular}{lcccc} 
Type & \multicolumn{3}{c}{ Material } & Total \\
& Flint & Chert & Chalcedony & \\
Scalene triangle & 150 & 35 & 4 & 189 \\
\hline Double-backed scalene & 12 & 4 & 2 & 18 \\
\hline Triangle & 14 & 2 & 0 & 16 \\
\hline Crescent & 29 & 3 & 0 & 32 \\
\hline Fine point & 31 & 9 & 4 & 44 \\
\hline Leaf point & 10 & 0 & 0 & 10 \\
\hline Oblique truncation & 43 & 5 & 0 & 48 \\
\hline Truncation & 2 & 0 & 0 & 2 \\
\hline Backed bladelet & 28 & 3 & 1 & 32 \\
\hline Double-backed blade & 8 & 1 & 0 & 9 \\
\hline Trapezoid & 0 & 1 & 0 & 1 \\
\hline Irregular & 5 & 1 & 0 & 6 \\
\hline Fragmentary & 47 & 3 & 0 & 50 \\
\hline Total & 379 & 67 & 11 & 457
\end{tabular}




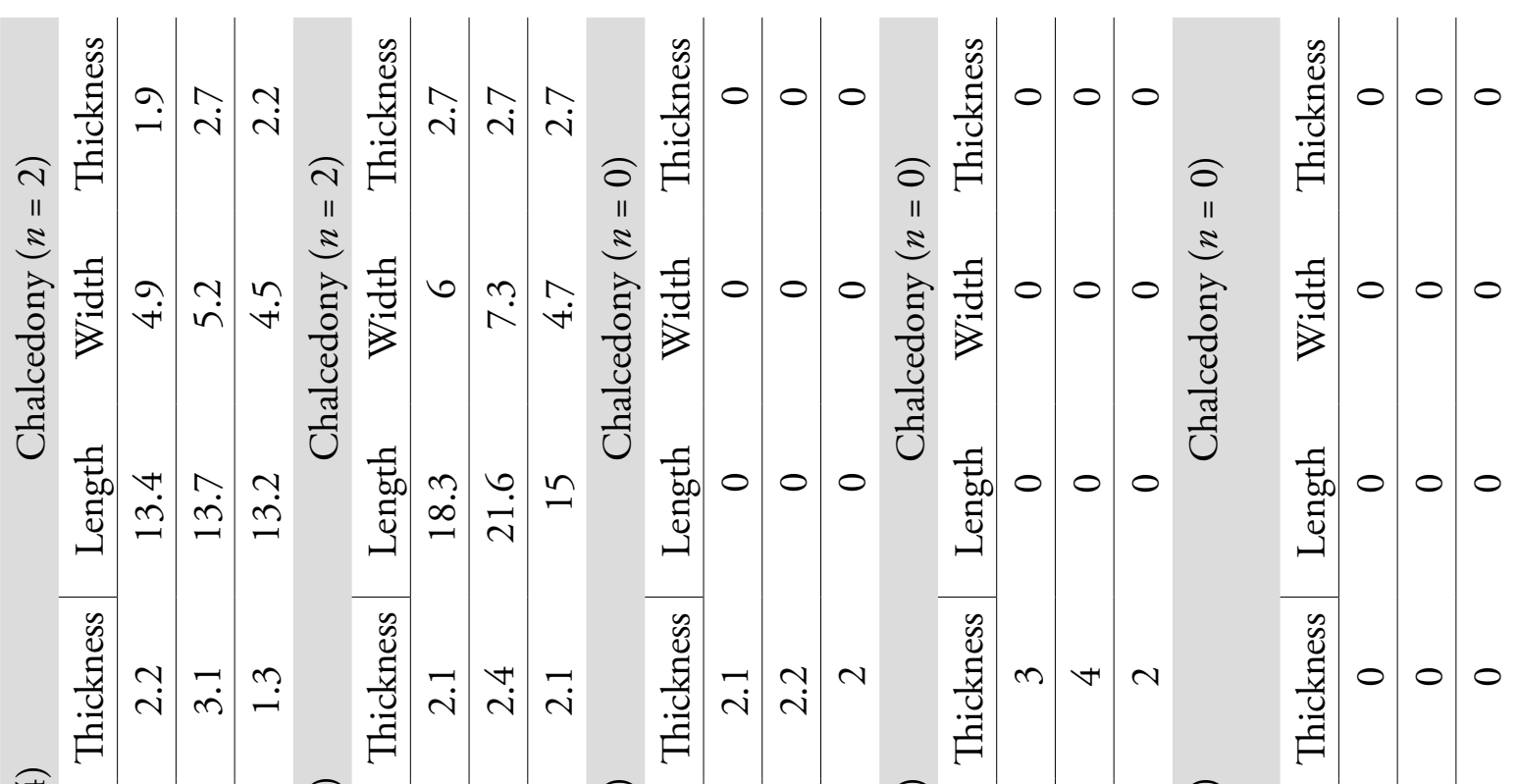

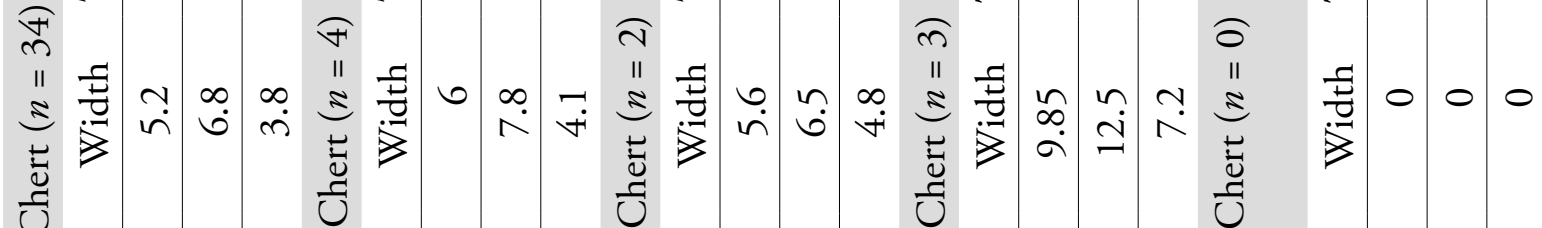
U⿺辶万

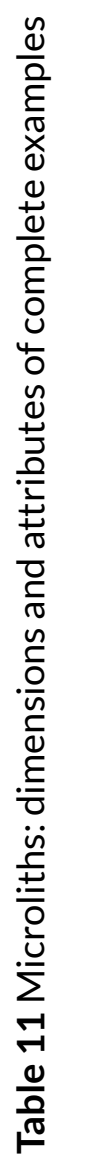
营

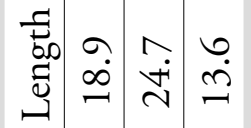

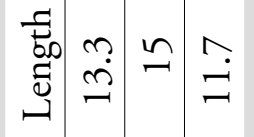

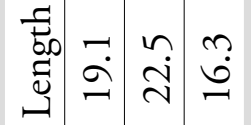
$\begin{array}{lllll}\frac{5}{5} & 0 & 0 & 0\end{array}$

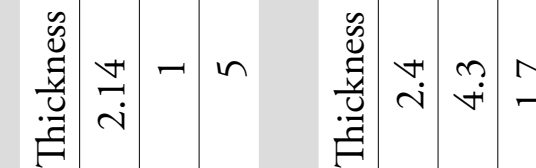

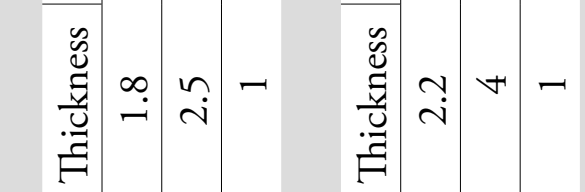

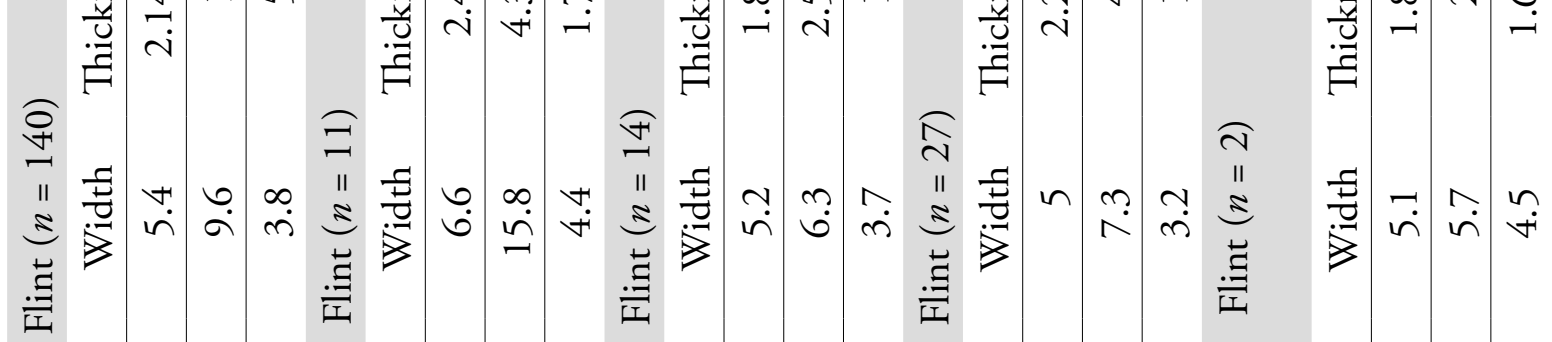

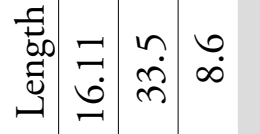

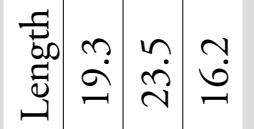

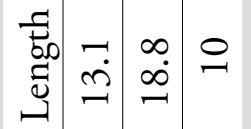

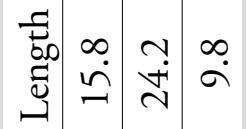

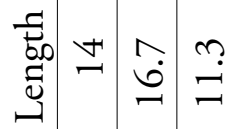

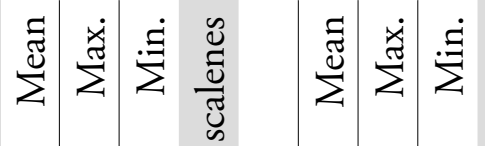

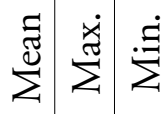

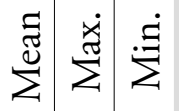

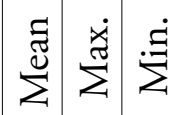

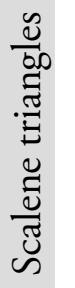

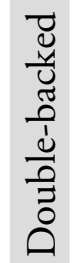
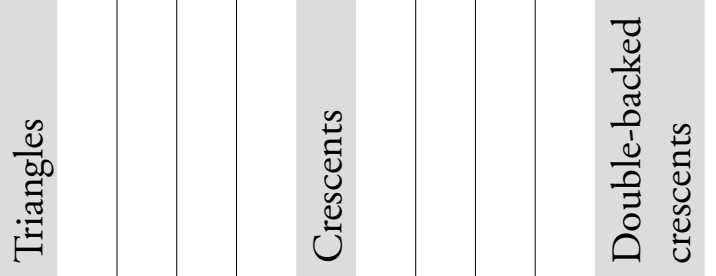


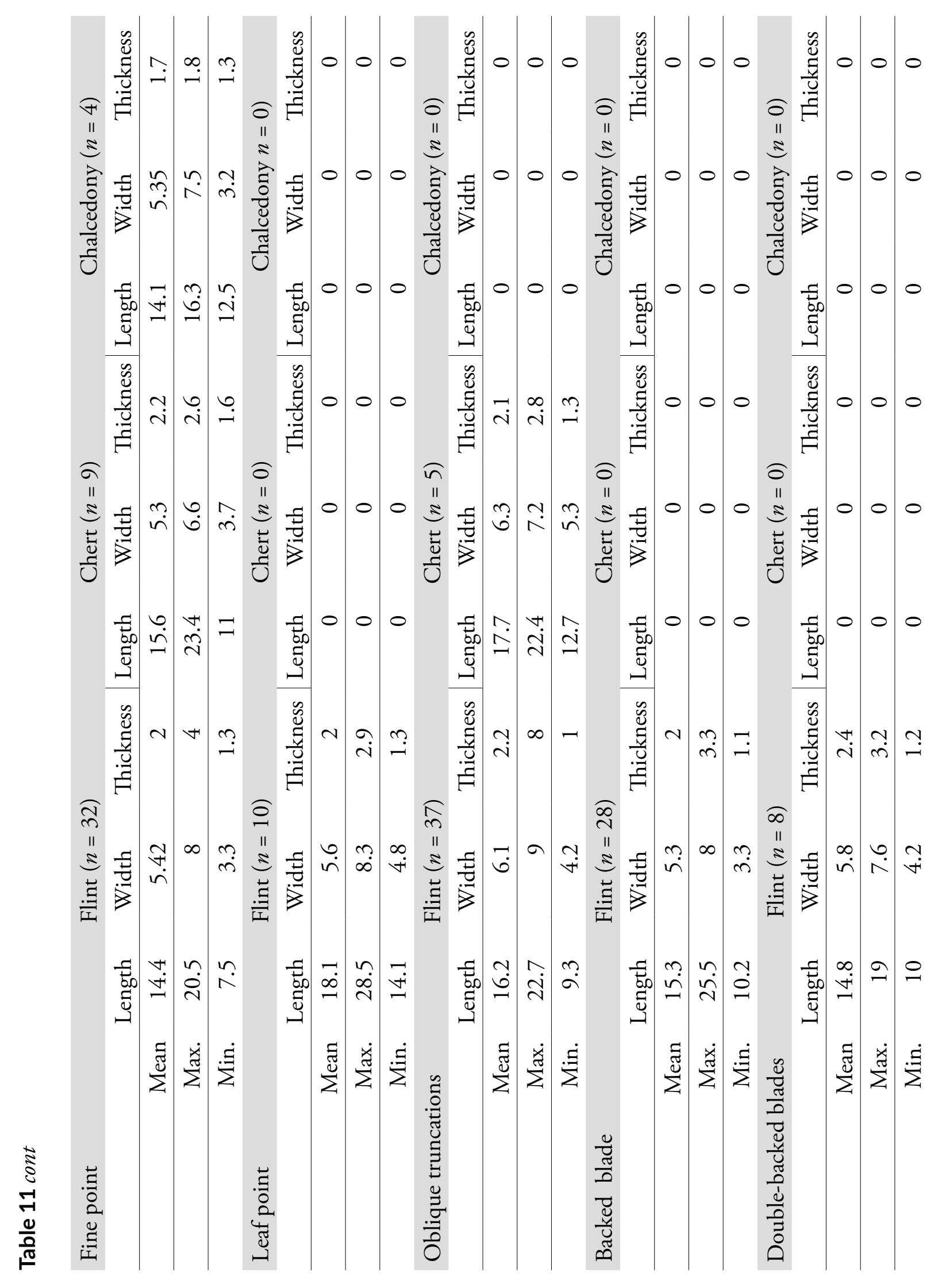


more detailed typological analysis. The dimensions and attributes derived from this sample are presented in Table 11.

\section{Scalene triangles and double-backed scalene triangles} (n 207)

Scalene triangles predominate and account for $46.7 \%$ of the total number of microliths within the assemblage. The majority are made on flint, with 39 on chert and six on chalcedony. $29.3 \%$ are patinated, with $16.6 \%$ burnt or heat affected. Of the 207 recovered pieces, eight are fragmentary, yet complete enough to be unequivocally recognised as scalene in character. Only the dimensions of complete pieces are given in Table 11 .

The scalene triangles are characterised by a generally small size and narrow shape. Four examples (Illus 11) are extremely thin and elongated in form. Those scalene pieces made on flint are the largest in size followed by those made on chert and chalcedony. This is in contrast to the dimensions provided by the other microlith categories in which the chert is narrowly larger (Table 10). However, it must be noted these were dimensions taken from much smaller proportions of chert microliths. A mean length of $16.11 \mathrm{~mm}$ was taken for the flint pieces compared with $15.7 \mathrm{~mm}$ for the chert and $13.4 \mathrm{~mm}$ for the chalcedony pieces. The mean widths and thicknesses gave a similar progression (Table 11). A large variation in size was noted in the samples of both flint and chert. The former provided a maximum $/$ minimum length of $33.5 \mathrm{~mm} / 8.6 \mathrm{~mm}$. Although not as marked within the chert sample the disparity was still sizeable, with the maximum/minimum length being $24.4 \mathrm{~mm} / 11.7 \mathrm{~mm}$.

Eighteen have blunt, microlithic retouch applied to the opposite long edge of the piece and are described here as double-backed (Illus 11 SF 7774). This retouch either extends along the complete length of the edge or is confined to the angle of the two longest edges (Illus 11 - SF 1229). The double-backed examples were larger than the regular scalenes in all three raw materials in which they were made, yet followed the same hierarchical size progression. However, the mean, maximum and minimum dimensions are consistently closer together and display few of the size disparities recognised in the regular scalene pieces (Table 11).

\section{Oblique truncations (n 48) (Illus 12 - SF 1168)}

Obliquely truncated microliths provided the next most numerous type, accounting for $10.5 \%$ of the microlithic assemblage. Flint provided 43 pieces, with five occurring on chert. Five were fragmentary yet considered complete enough for confident categorisation. Patination was present on 16 examples and eight were burnt.

All the pieces appeared to have been made on bladelets blunted by microlithic retouch along the left or right lateral edge. The pieces are generally quite small, with those made on chert being slightly larger than those on flint (Table 11).

These pieces can be more correctly described as obliquely truncated points as the retouch generally truncates the bladelet to a fine, sharp point.

Triangles (Illus 12 - SF 6694)

Fourteen flint and two chert microliths were identified as isosceles triangles having two equal retouched sides. They appear to be the smallest of the microlith categories with a size range ranging from $10 \mathrm{~mm}$ to $18.8 \mathrm{~mm}$ in length and a width ranging from $3.7 \mathrm{~mm}$ to $6.5 \mathrm{~mm}$ (Table 11 ).

\section{Fine points (Illus 12 - SF 7767 and SF 6704)}

Fine-point microliths are the third most numerous of the complete microlith sub-categories, accounting for $9.9 \%(n 44)$ of the total. Thirty-one are made on flint with a further nine occurring on chert and four on chalcedony. Those made on chert appear slightly larger than those on flint, with the smallest being made on chalcedony (Table 11). All the pieces are characterised by having fine microlithic retouch applied along both lateral edges, converging into a point. This is often very 'needle-like' in form.

\section{Leaf points}

The leaf points form a less numerous microlithic point category, with only 10 recognised examples, all occurring on flint. In general they are slightly larger than the fine-point form with a mean length/width of $18.1 \mathrm{~mm} / 5.6 \mathrm{~mm}$ (Table 11 ). With the exception of SF 1215 and SF 1180 (Illus 12), which have double-sided retouch, the pieces are retouched along one side, which converges with the un-retouched edge to form a point (eg Illus 12 - SF 1193). The retouched edge tends to be slightly curved in form. 

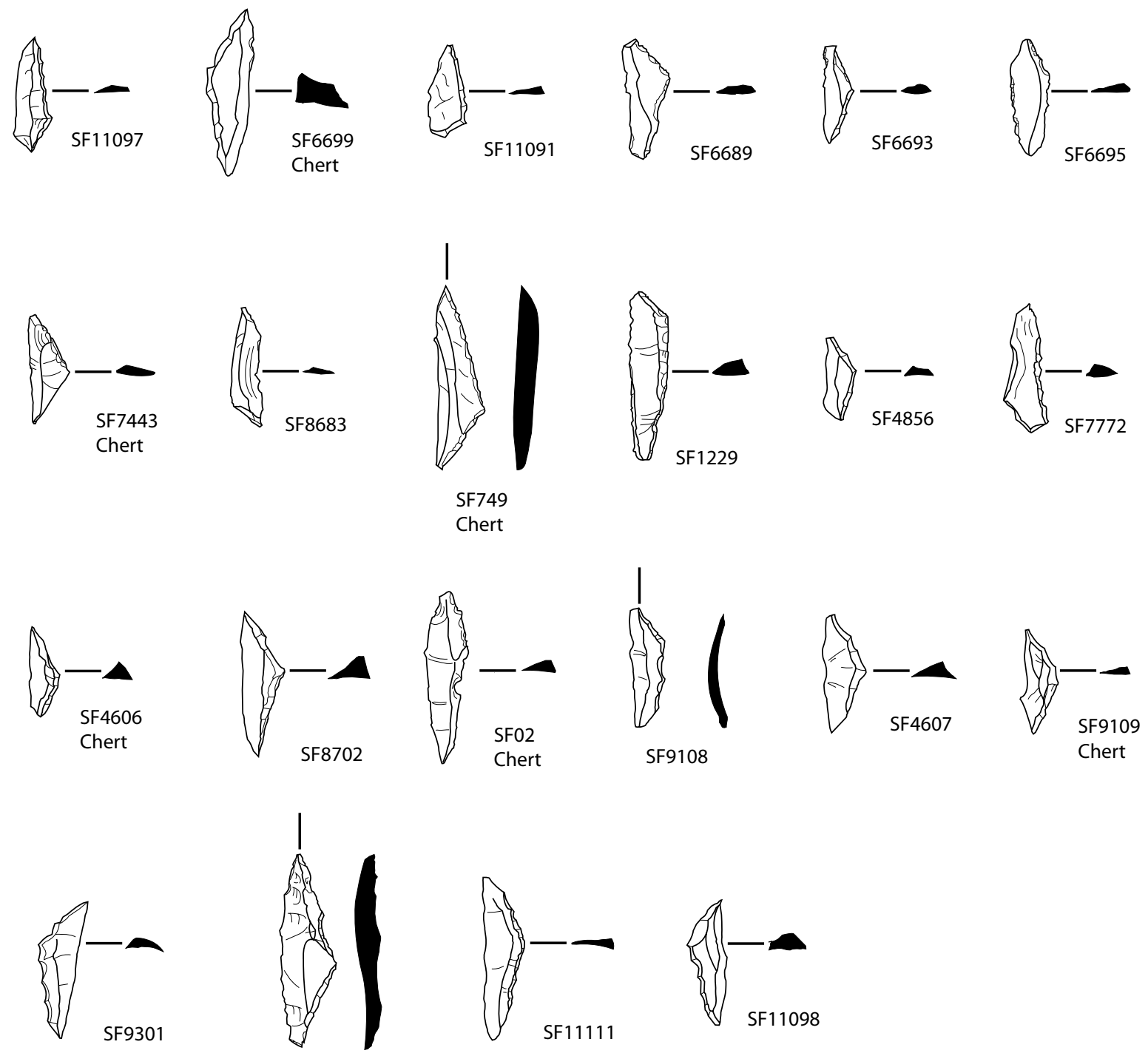

SF1259

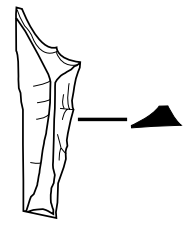

SF9292

Oblique truncation on blade

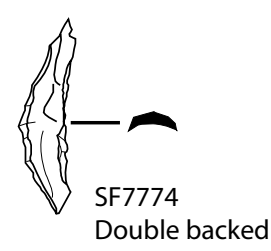

SF7774
Double backed

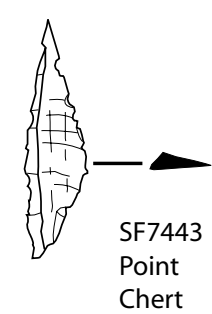

Chert
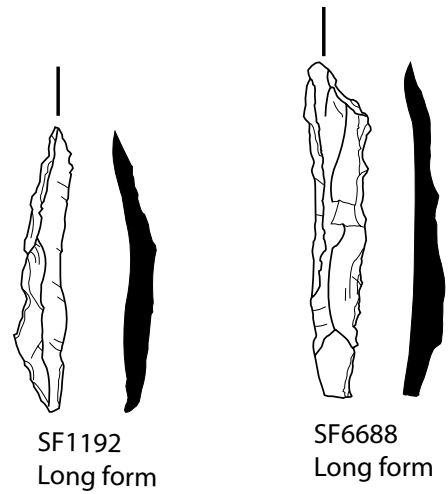

0 $100 \mathrm{~mm}$

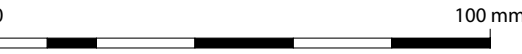

Illus 11 Microliths - scalene (flint unless otherwise indicated) 


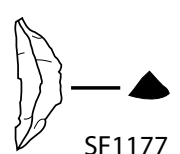

Crescent

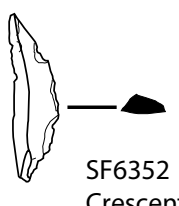

Crescent

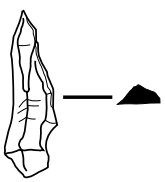

SF4859

Obliquely

backed blade
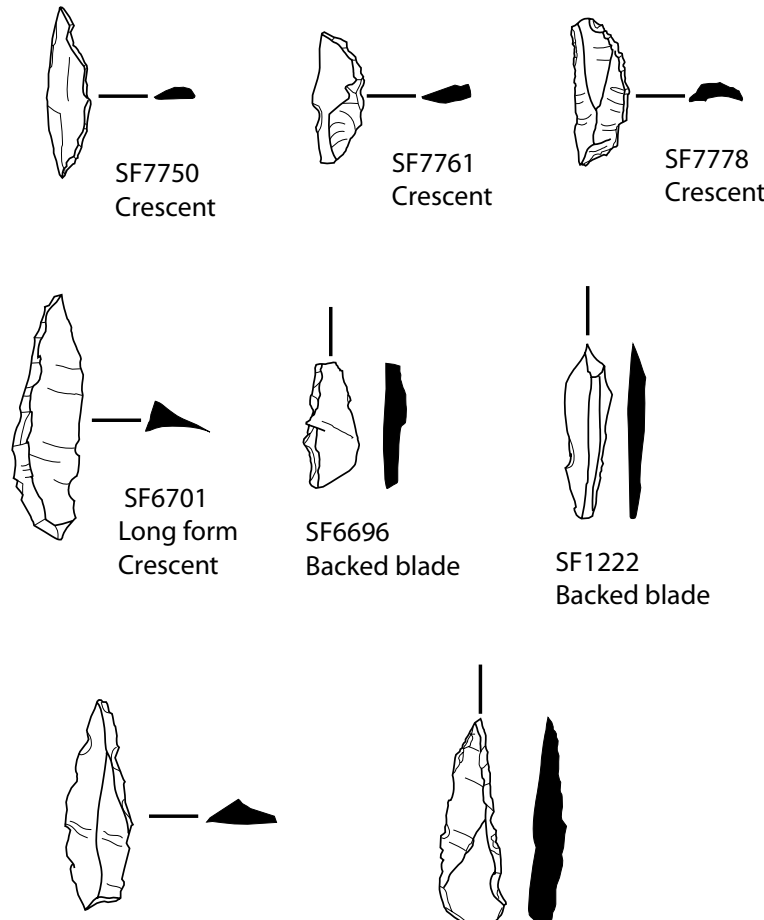

SF03

Double backed blade

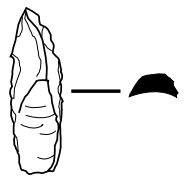

SF7767

Point

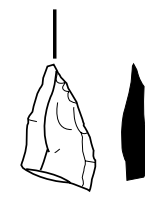

SF1193

Point

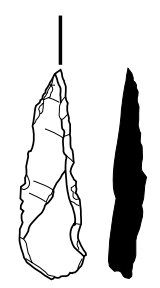

SF1224

Obliquely truncated backed blade

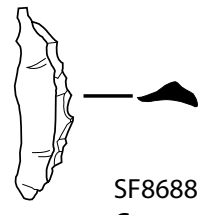

Crescent

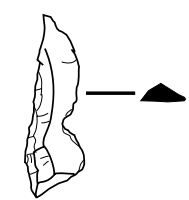

SF337

Backed blade with notch

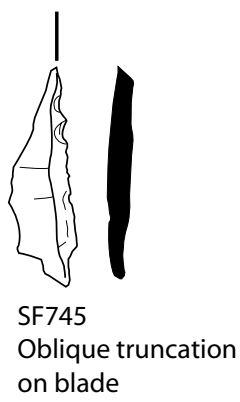

Oblique truncation

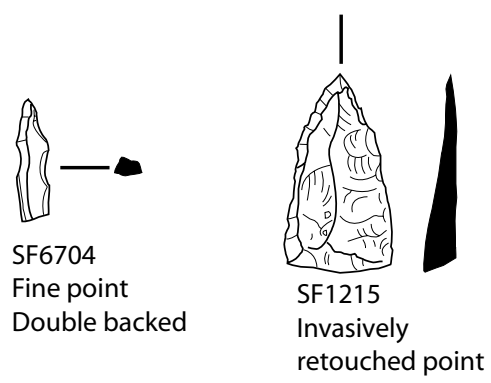

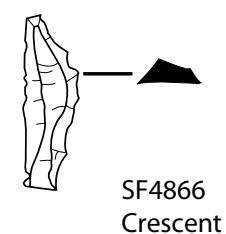

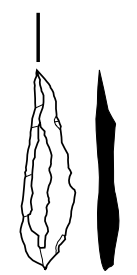

SF1217

Obliquely

backed blade

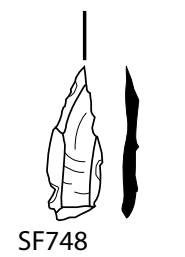

Oblique truncation on blade

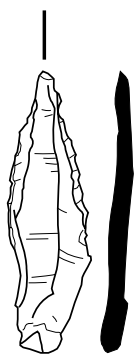

SF1180

Shoulder point
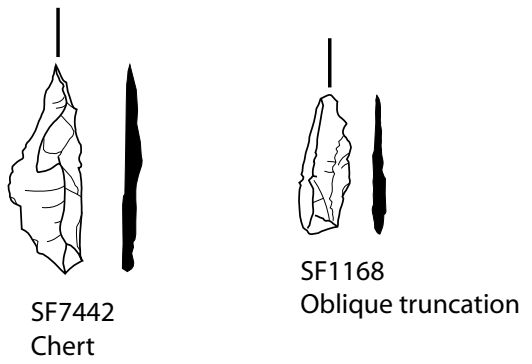

Oblique truncation

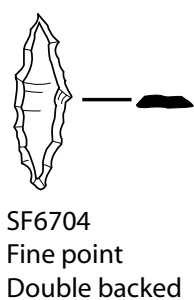

Double backed
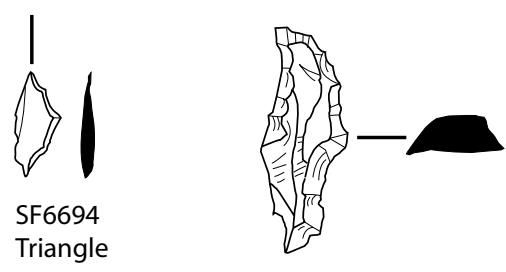

SF6708 Irregular

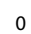


Backed bladelets (Illus 12 - SF 6696, SF 1222, SF 337, SF 1217, SF 4859, SF 03, SF 1224, SF 745, SF 748 )

Thirty-two backed bladelets were recovered, all made on flint. All the pieces are characterised by having microlithic retouch along one lateral edge. This is mostly straight and oblique but some slightly curved and more irregular forms are present. The mean length/width of the artefacts is $15.3 \mathrm{~mm} / 5.3 \mathrm{~mm}$.

\section{Double-backed bladelets}

As with the scalene and crescent categories, a doublebacked form of bladelet is present with retouch applied along both lateral edges. Nine of these were retrieved at East Barns, eight made on flint, one on chert. The double-backed variant appears to be of similar size to the regular backed bladelet form, with a mean length/width of $14.8 \mathrm{~mm} / 5.8 \mathrm{~mm}$.

Crescent/double-backed cresents (Illus 12 - SF 1177 , SF 7750, SF 7761, SF 7778, SF 8688, SF 4866 and $S F$ 6352)

Thirty-two crescent-shaped microliths were recovered, of which 29 occurred on flint and three on chert. Crescents are microliths defined by the application of retouch that creates a crescentic shaped lateral edge. At East Barns two doublebacked pieces were also retrieved. These pieces also have retouch applied along the straight lateral edge of the microlith. The crescent microliths are generally of small size, with maximum/minimum dimensions ranging from $24.2 \mathrm{~mm} / 9.8 \mathrm{~mm}$ in length to $12.5 \mathrm{~mm} / 3.2 \mathrm{~mm}$ in width.

\section{Trapezoid/truncations/irregular microliths}

A single chert trapezoidal microlith was identified along with two microlithic truncations and five irregular pieces, all made on flint. The irregular microliths are a range of forms that do not appear in the classificatory systems used by either the SHMP or at Kinloch Farm. These pieces tend to have irregular shapes and retouch (Illus 12 - SF 6708).

\section{Fragmentary microliths}

Fifty microliths were classified as being fragmentary, ie the piece was not considered complete enough to place it within one of the other typological categories. A closer examination revealed that the majority of these pieces were probably scalenes.

\section{Table 12 Scraper types}

\begin{tabular}{lccccc} 
& Flint & Chert & Chalcedony & Quartz & Total \\
Short convex & 67 & 2 & 1 & 2 & 72 \\
\hline Short thick convex & 2 & 0 & 0 & 0 & 2 \\
\hline Wide convex & 49 & 4 & 1 & 0 & 54 \\
\hline Long convex & 1 & 2 & 0 & 0 & 3 \\
\hline Concave & 11 & 3 & 0 & 0 & 14 \\
\hline Disc & 8 & 0 & 0 & 0 & 8 \\
\hline Angled & 64 & 4 & 2 & 0 & 70 \\
\hline Sub-angled & 43 & 2 & 0 & 0 & 45 \\
\hline Denticulate & 7 & 0 & 0 & 0 & 7 \\
\hline Straight & 32 & 1 & 1 & 1 & 35 \\
\hline Irregular & 29 & 1 & 3 & 0 & 33 \\
\hline Fragment & 16 & 0 & 1 & 0 & 17 \\
\hline Scraper edge rejuvenation flake & 6 & 1 & 0 & 0 & 7 \\
\hline Possible scraper & 1 & 0 & 0 & 0 & 1 \\
\hline & & & & & 368
\end{tabular}




\subsubsection{Scrapers}

After microliths, scrapers form the next most numerous category of modified artefact recovered at East Barns. 368 pieces (1.2\%) were identified and placed within the 14 typological categories shown in Table 12. These include fragmentary pieces $(n 17)$ and scraper edge rejuvenation flakes ( $n 7) .115$ pieces showed signs of burning or being heat affected. A further 99 showed visible degrees of patination. It has been noted that little in-depth work has been done on scraper technology from assemblages with secure Mesolithic contexts; therefore, the classification of the scrapers from East Barns closely follows that outlined within the SHMP (Finlayson et al 2000: 68-9). This is in order to aid intra-site comparison with other recently published Mesolithic assemblages and to provide a building block for further study.

Scraper morphology is recognised as highly variable and difficult to place chronologically with any great accuracy (Finlayson et al 2000: 583). Although the majority of the scrapers associated with the occupation of the house fit happily into existing Mesolithic classifications such as that of Wickham-Jones \& McCartan (1990), it must be noted that many of the types presented here and in other Mesolithic assemblages are also to be found in later prehistoric deposits. Given that a number of dated later Mesolithic and Neolithic deposits were excavated both cutting Mesolithic deposits within the area of the house (C2574) and as deposits within its immediate vicinity (Contexts 2582, 2562 and 2531), a number of scrapers from the assemblage may be of later date. Similarly, the colluvial deposits of the hollow infilling the house, such as C2518 and C2533, may also contain scrapers of a later chronological date.

Although the scrapers may have come from a variety of chronological deposits, it would appear that the majority were fashioned on retouched flakes, with many retaining cortex showing that scraper manufacture was relatively simple and utilitarian. Primary or secondary flakes were often chosen, probably on grounds of thickness and functionality. The seven scraper rejuvenation flakes present show that some curation was also practised.
Scrapers occurred in all four of the major raw materials, with flint providing 336 , chert 20 , chalcedony nine and quartz three.

A sample of each category is illustrated in Illus 13 and a short description is given below.

\section{Short convex}

The most numerous of the scraper categories, short convex forms, were found in all four of the main raw materials, with 67 occurring on flint, two on chert, one on chalcedony and two on quartz. These scrapers have a single convex scraper edge less than $10 \mathrm{~mm}$ thick. All but two have the working edge situated at the distal end.

This scraper category was morphologically very varied and ranged from simple end-scraper types on primary flakes to very small invasively flaked 'micro' scraper types. These latter pieces must have been too small to adequately work with the fingers and it is likely that they were hafted. Four examples were identified as made on core rejuvenation flakes while one occurred on a platform core fragment and one on a chunk. Four pieces showed a marked narrowing of the piece away from the working edge (Illus 13 - SF 6654). This may also have been employed in order to facilitate hafting.

\section{Wide convex (Illus 13 - SF 6655)}

These scrapers have a scraping edge situated along the longest lateral edge and can also be termed convex side-scrapers. Of the 54 pieces, 49 are on flint with four on chert and one on chalcedony.

Wide convex scrapers are much less varied in form than the short convex type, with the majority made on flakes. A single piece was identified on a bipolar core remnant.

\section{Long convex and short thick convex}

There were three and two pieces respectively in these categories. All are made on flint. The latter has a convex scraping edge more than $10 \mathrm{~mm}$ thick while the former is a short convex scraper but twice as long as wide. All are made on flakes.

\section{Concave}

Fourteen concave scrapers were recovered, 11 on flint and three on chert. Concave scrapers have a working edge that is concave or hollow in profile. All had the working edge on the distal end of the 


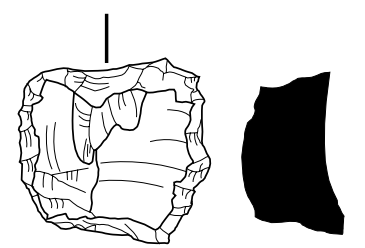

SF11080

Angled
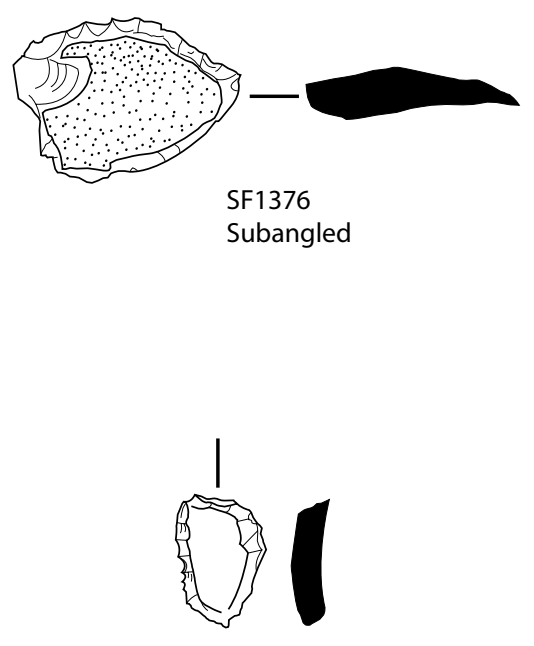

SF4827

Subangled microscraper

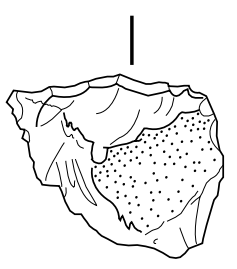

SF1322

Straight

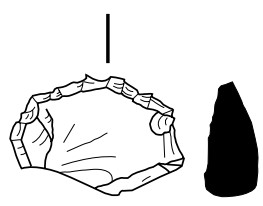

SF6655

Wide convex

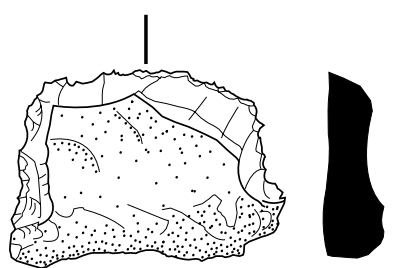

SF7723

Angled
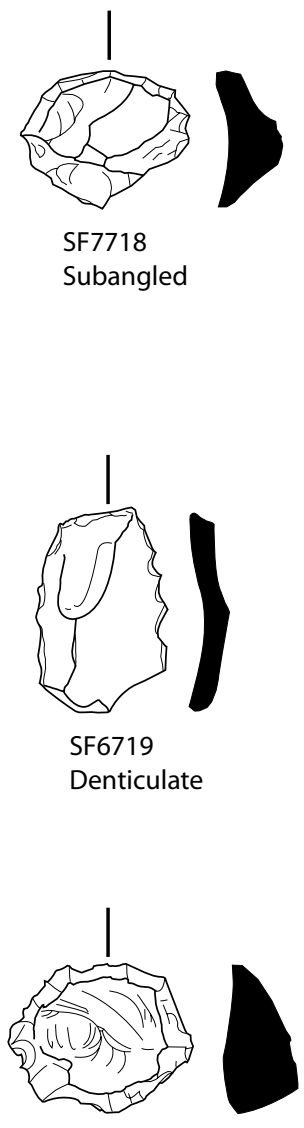

SF1338

Short disc thumbnail

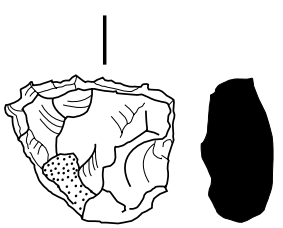

SF11073

Angled invasively flaked
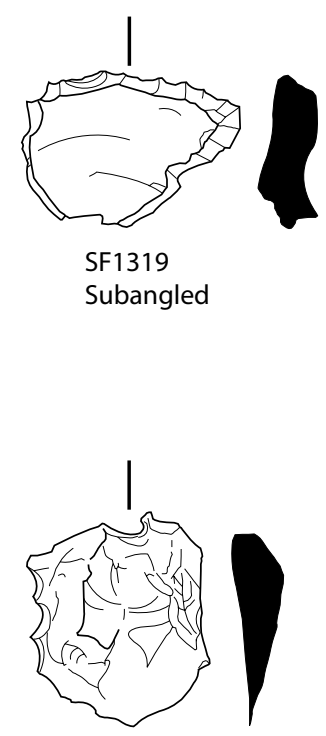

SF6659

Denticulate scraper

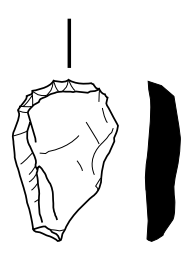

SF6654

Short convex

Illus 13 Scrapers (all flint) 
piece. In one example the working edge had been worked transversely.

Disc

Eight pieces were identified as disc scrapers, all of flint. These pieces had retouch applied around the entire circumference of the flake. All are generally small in size.

\section{Angled}

Seventy pieces were identified as being angled. All have more than one scraping edge meeting with sharp corners. Sixty-four are made on flint with four on chert and two on chalcedony. Most of the pieces are made on the distal end of flakes. One example is invasively flaked (Illus 13 - SF 1338).

\section{Sub-angled}

Forty-five scrapers are sub-angled and have more than one working edge meeting with rounded corners (Illus 13 - SF 1319 and SF 1376). Fortythree are made on flint, with two on chert. The subangled category contains a number of small, almost micro-sized examples, with one example which appears to have a chamfered proximal end, possibly for hafting within a stick (Illus 13 SF 4827). All but one sub-angled scraper is worked at the distal end.

\section{Denticulate}

Seven pieces on flint are denticulated, ie the working edge has multiple small notches, creating a saw effect (Illus 13 - SF 6719 and SF 6659). The majority appear worked along the distal end of flakes.

\section{Straight}

The 35 scrapers in this category had a continuous scraping edge that is neither convex nor concave (Illus 13 -SF 1322). Thirty-two were on flint with single pieces on chert, chalcedony and quartz. The majority are retouched across the distal end or along the right-hand lateral edge of flakes. However, five have retouch applied along both lateral edges and two are on blades. A single piece is made on a chunk.

\section{Irregular}

The 33 pieces in this category were complete scrapers with retouch that could not be fitted into the other categories. Twenty-nine were on flint, with three on chalcedony and a single piece on chert. These pieces are morphologically varied, with many appearing to combine categories. The majority are made on flakes, with the exception of two fashioned on blades and one on a platform rejuvenation flake.

\section{Fragmentary}

Seventeen scraper fragments were identified, 16 of which were on flint and a single piece on chalcedony.

\section{Scraper rejuvenation flakes}

Seven pieces were identified, six on flint and one on chert. Like the majority of the platform rejuvenation flakes, these pieces were created by side blows to the working edge.

\subsubsection{Microburins}

Fifty-two microburins were identified within the assemblage (Illus 14 - SF 7786, SF 6718 and SF 1161). Forty-five were made on flint with four on chert, one on chalcedony and two on quartz. The latter are problematic and though both display a notch and recognisable burin facet, these may be accidental.

Microburins are recognised as the snapped ends of bladelets and are usually seen as a waste product of microlith manufacture. In particular this category is linked with the manufacture of scalene triangles (Wickham-Jones \& McCartan 1990: 100).

The microburins range widely in size with maximum $/$ minimum dimensions of $23 \mathrm{~mm} / 8.7 \mathrm{~mm}$ in length and $18.8 \mathrm{~mm} / 4 \mathrm{~mm}$ in width. Of the 52 pieces, 33 were notched on the right-hand side, with 19 notched on the left.

\subsubsection{Notch-and-snaps (IIlus 14 - SF 6524, SF 6711, SF 6712, SF 1272, SF 7441, SF 7748, SF 756 and SF 16350)}

Although closely related to microburins, the 44 notched pieces provided a snap truncation rather than a burin facet. Of these, 40 were made on flint, one on chert and three on chalcedony. In size they were similar to the microburins, with a max $/ \mathrm{min}$ length of $28 \mathrm{~mm} / 8.4 \mathrm{~mm}$ and a width of $16.1 \mathrm{~mm} / 4.5 \mathrm{~mm}$. Notched pieces with simple snap truncations may be evidence of failed attempts at microlith production through the microburin technique (Saville 2005: 113). 

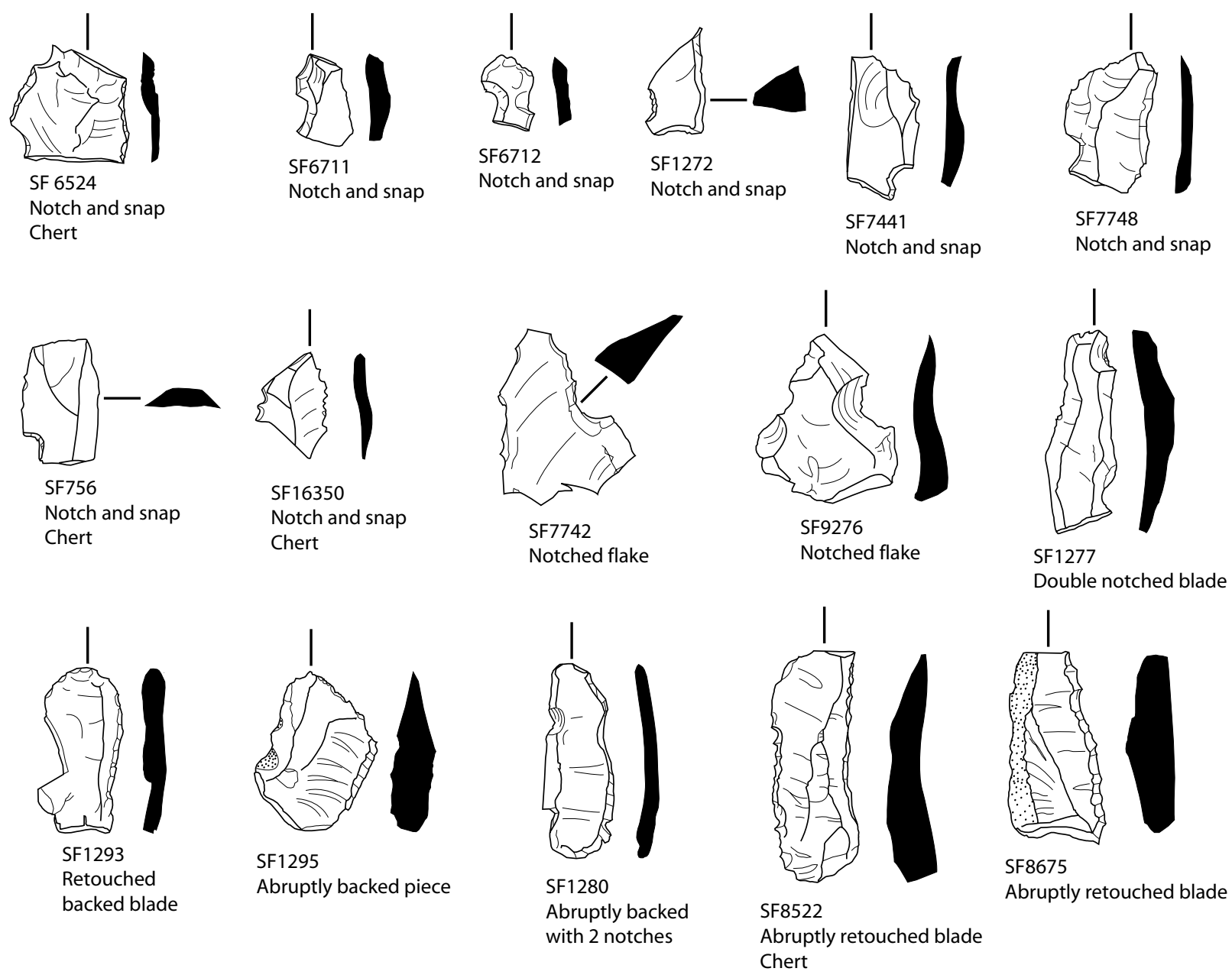

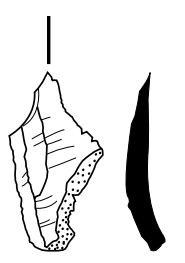

SF7786 Microburin

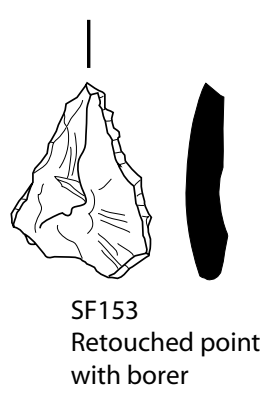

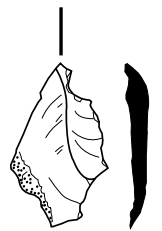

SF1161 Microburin

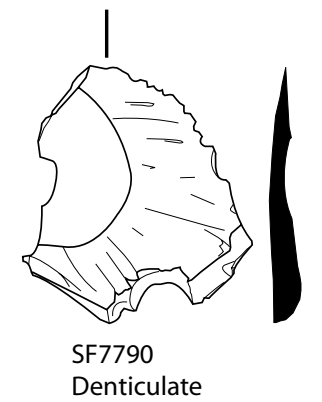

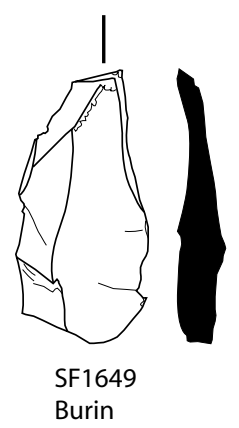

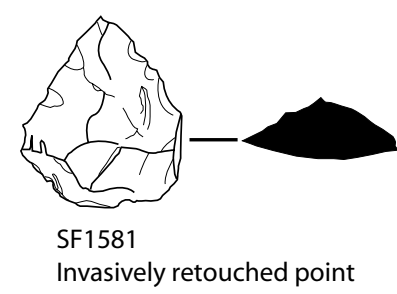

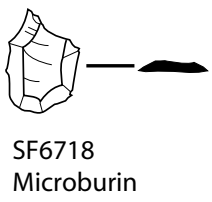

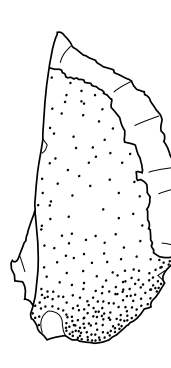

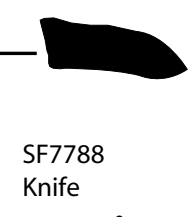

0 


\subsubsection{Lamelles a cran}

Only two Lamelles a cran were positively identified, both made on flint. Lamelles a cran are a possible long form of microburin and are another category assumed to be linked to the production of scalene microliths (Wickham-Jones \& McCartan 1990: 100). However, given the predominance of scalene triangles within the modified assemblage at East Barns together with the relative abundance of other associated classes such as microburins, notch-andsnaps and notched pieces, the scarcity of Lamelles a cran is noticeable.

Both pieces are proximal with retouched notching extending along the right-hand side and left-hand side. In size the Lamelles a cran are at the upper end of the microburin scale, with a mean length of $18.7 \mathrm{~mm}$ and a width of $12.35 \mathrm{~mm}$.

\subsubsection{Notched pieces}

Fifty-two pieces were characterised as notched. Forty-three were of flint, seven of chert and one each on chalcedony and quartz. These pieces occur on both flakes ( $n$ 32) (Illus $14-$ SF 7742) and blades/ bladelets (n 20) (Illus 14 - SF 1280) with three made on flake fragments. There is some difficulty in deciding which are functional or technological in form without a comprehensive programme of microwear being conducted. Nevertheless, given the relative abundance of microburins/notch-and-snaps a significant number are thought to be related to microlith production.

Three pieces are double-notched (Illus 14 SF 1277). A single example occurs on a platform rejuvenation flake.

\subsubsection{Denticulates}

Twenty-four denticulated flakes and blades/bladelets were identified. These pieces are characterised by multiple small notches or flake removals creating a serrated edge (Illus 14 - SF 7790). All were made on flint with the exception of three occurring on chalcedony. All but four occurred as flakes.

\subsubsection{Points}

A total of 33 pieces were classified as points. Twentyfour were made on flint, with five on chert, three on chalcedony and one on quartz. Seven showed degrees of patination and three were burnt. Both blades/bladelets and flakes had been modified by the application of retouch in order to produce a sharp working point. This modification varies in character from that of notches applied to create a sharp ' $b e c$ ' (Illus 14 - SF 153) to that of fine semi-abrupt retouch converging along lateral edges (Illus $14-$ SF 1281). Several appear to take the form of possible combination tools or reworked pieces from other categories. The size of this category is just as varied, with lengths ranging from $7.8 \mathrm{~mm}$ to $28.5 \mathrm{~mm}$ and widths from $7 \mathrm{~mm}$ to $22.7 \mathrm{~mm}$.

The uses of such tools would probably be as varied as their size and morphology. The larger and coarser of the pieces may have served as gravers, while other domestic tool types such as piercers, borers and awls are all undoubtedly represented. A few of the finer examples may even have served as projectile points.

\subsubsection{Edge retouched pieces}

Edge retouched pieces other than those described in the categories above account for $9.3 \%$ ( $n 108)$ of the modified assemblage. All had retouch regular enough to be identified as being deliberately modified.

The edge retouched pieces occurred on both flakes (Illus 14-SF 1295) and blades (Illus 14 - SF 1293 and SF 1280), with larger blanks being favoured for the latter. A small range of other pieces such as chunks and platform rejuvenation flakes were also modified.

Twenty-five of the pieces were patinated, with a further 12 being burnt or heat affected. Flint again dominated, producing 95 pieces; 11 were made on chert and two on chalcedony. The retouch is regular and is largely restricted to the lateral edges, although proximal and distal examples are present.

The category was divided into five further subcategories: thin-backed retouch, thick-backed retouch, abrupt, truncations and retouched.

\section{Thin-backed pieces}

Thirty-three pieces showed fine regular edge retouch. Twenty-one of the pieces were on recognisable flakes or flake fragments, two were on blades, one was made on a chunk and one on a side-struck platform rejuvenation flake. Five of the flake pieces were fragmentary. In all but two examples the retouch 
was fairly abrupt. The two others have semi-acute retouch applied to a lateral edge and therefore can possibly be viewed as simple knives.

Three of the pieces were retouched along the right-hand side, with 10 along the left. Two were retouched across the distal end of the piece and two were also worked across the proximal end. Two pieces had retouch applied to both lateral edges. SF 40 had fine abrupt retouch applied to the left lateral edge, whereas the right-hand side appears to have a slight concave scraping edge. It would appear that in most of the pieces edge trimming served to back the piece for easier handling or hafting.

The complete thin-backed flakes gave a max/ min length range of $6.8 \mathrm{~mm} / 49.6 \mathrm{~mm}$ and a width range of $6.2 \mathrm{~mm} / 27.7 \mathrm{~mm}$. The two blades were large examples with lengths of $32 \mathrm{~mm}$ and $26.8 \mathrm{~mm}$ and widths of $10 \mathrm{~mm}$ and $12.2 \mathrm{~mm}$ respectively.

\section{Abruptly retouched pieces}

These are similar in morphology to the thin-backed examples, although the retouch is larger and blunter. Thirty-eight pieces were identified, with four made on chert and the remainder on flint. Recognisable flakes account for nine of the blanks used, with nine blades. Ten of the pieces were fragmentary. Retouch occurred on all edges, with lateral modification of the left-hand side being the most common. Three of the blades were retouched along both lateral edges (Illus 14 - SF 8522). Two pieces had blunting retouch along a single edge with presumed occasional use-wear.

The complete abruptly retouched flakes gave a $\mathrm{max} / \mathrm{min}$ length range of $28.2 \mathrm{~mm} / 12.2 \mathrm{~mm}$ and a width range of $13.2 \mathrm{~mm} / 6.4 \mathrm{~mm}$. The blades were relatively large examples, with lengths ranging from $35.7 \mathrm{~mm}$ to $13.4 \mathrm{~mm}$ and widths of $10.8 \mathrm{~mm}$ and $19.2 \mathrm{~mm}$ respectively.

\section{Thick-backed pieces}

Four pieces were catalogued as thick-backed. All were made on flint. Three were flakes, with a single piece made on a blade. All four were characterised as thicker pieces with steep, abrupt and less regular retouch. The pieces have a max/min length of $34.8 \mathrm{~mm} / 13.4 \mathrm{~mm}$ and a width of $10.3 \mathrm{~mm} / 7 \mathrm{~mm}$. It is possible that these pieces represent small fabricators.

\section{Truncations}

Nineteen pieces were catalogued as truncations. Unlike the SHMP typology, this study has avoided terming them as 'microlithic truncations' because the retouch truncating the piece varies significantly. However, it seems probable that some are indeed related to microlith manufacture. Sixteen are made on flint, with the remainder on chert. Nine pieces are made on blades, of which two are fragmentary. The remaining 11 are on flakes only, one of which is fragmentary. Thirteen of the artefacts have been obliquely truncated, with four truncated across the distal and two across the proximal end. A single piece truncates a denticulated flake and another truncates a blade with fine regular retouch. A single piece has a small notch underlying the truncation; this piece may represent a failed attempt at microlith manufacture.

The size of the pieces varies considerably, with $\mathrm{max} / \mathrm{min}$ length of $30.6 \mathrm{~mm} / 11.3 \mathrm{~mm}$ and a width of $19.4 \mathrm{~mm} / 5.7 \mathrm{~mm}$.

\section{Other retouched pieces}

This category includes five pieces all made on flint. These pieces do not fit easily into any of the other modified categories due to morphology. In the main these pieces exhibit retouch that differs significantly from the other modified pieces within the assemblage, and it is possible that some are related to later prehistoric activity.

\subsubsection{Possible burins}

Twenty possible burin-struck blanks (Illus $14-\mathrm{SF}$ 1649) were identified, 15 made on flint and five on chert. It is likely that many of these pieces are the result of proximal spalling occurring during removal.

\subsection{Spatial analysis and material distributions}

\subsubsection{Introduction}

Unlike the majority of Mesolithic sites, the excavation at East Barns produced coherent structural remains with considerable in situ deposits. The site area itself was contained within a natural hollow, a situation which appears to have encouraged the build-up of overlying and infilling layers of colluvial silt. These deposits effectively sealed the underlying 
archaeology and have therefore protected it from the erosional nature of modern farming practices.

The East Barns house also appears to have been restricted to a single main construction phase, unlike, for example, the Mesolithic house excavated at Howick (Waddington 2007). However, the presence of numerous conjoined and closely spaced post holes would suggest efforts at probable repair, if not reconstruction. In situ occupation deposits were identified both within and outwith the house in the form of an intermittent refuse deposit, occupation horizons and pit fills.

In order to gain any meaningful insights from intra-site artefact distributions, it was necessary to disregard any re-deposited lithic material and focus solely on those artefacts contained within the in situ occupation deposits and features. All modified tool and debitage categories retrieved from these deposits with the exception of the pit fills were plotted (Illus 15-19).

All artefactual material retrieved during the excavation was recorded using a strictly controlled grid system (see Section 3.1, Methodology). The material was recovered through both hand excavation and the on-site wet-sieving of all excavated deposits. This method enabled large amounts of material to be quickly processed and for the material to be both spatially and temporally identified with a fair degree of accuracy.

\subsubsection{General material distribution}

The vast majority of artefacts were recovered from deposits directly associated with the house. These included the occupation horizons immediately surrounding the house (Contexts 2549, 2561, 2564 and 2567) and the intermittent refuse deposit found within the interior of the structure itself (C2573). In situ lithic material was also recovered from both external and internal pit features. Nevertheless, a large proportion of the assemblage was retrieved from the infilling colluvial deposits. These were almost certainly incorporated into the house, either by being washed in from the surrounding occupation horizons or by being deliberately dumped within the hollow once the structure had passed out of use.

Twelve pits and post holes excavated within the immediate vicinity of the house provided a further 956 lithics. These included 28 modified tool types (microliths, scrapers and retouched). Seven of the pits are located within the occupation horizons lying to the north and west of the structure. A small cluster of four pit features was located to the immediate north-east and a single large pit was positioned to the east. It is likely that the majority of these features represent waste pits. As such, the lithic material they contain is of limited value in determining on-site spatial patterning and has therefore been omitted from the more detailed distributions given below.

Five internal pits and deposits were excavated within the central area of the structure. These included Hearth Feature 2677, from which 157 lithics were retrieved, and included a scraper, three scalene triangle microliths, a fine point and a backed blade. The pits produced 335 lithic artefacts. A further three scalenes, a scraper and two other microliths were found within the other pit fills.

A stratigraphically visible fall-off in the total amounts of lithic material retrieved from the deposits is apparent. The in situ deposits consisting of the activity floors and the house detritus produced a total of 4,562 artefacts. The infilling deposit (C2550) which immediately overlay the structural elements of the house and the detritus deposits produced even more, with a total of 6,380. This deposit was considered the primary infill of the house after abandonment, which may explain the large number of lithics. The four sequentially overlying infills of colluvium then produced a rapid fall-off in numbers: C2546 $=2,663, \mathrm{C} 2533$ $=2,575, \mathrm{C} 2518=996$ and C2521 $=48$. A similar stratigraphic fall-off in numbers was identified within the Mesolithic structure excavated at Echline Fields (Robertson et al 2013: 111). Interestingly, the topsoil overlying the immediate vicinity of the East Barns house produced negligible numbers of lithic material. This suggests that all activity areas associated with the structure were confined to the extent of the hollow and remained relatively intact.

\subsubsection{Temporal distinctions}

No strong temporal distinctions can be observed from the distribution of the majority of the lithic material associated with the structure. A broadly similar mix of debitage and Mesolithic artefact 
categories was found in all of the associated stratified deposits. However, later activity was observed within the area of the structure in the form of the two large flint knives recovered from Neolithic deposits and the colluvial layer (C2533) lying immediately above.

Neolithic activity was also noted at the northern end of the hollow, where several pits produced Neolithic dates and associated pottery. A later Mesolithic activity floor (C2531) dating to 4800-5000 cal BC was revealed to the immediate south of these features. This floor produced a relatively low number of lithics $(n$ 109) and included no microlithic artefacts or other modified tool categories. Core types were restricted to four platform examples. Quartz was the dominant raw material within this context, accounting for over $80 \%$ of the recovered lithics.

Interestingly, there were no broad-blade microlithic types present in the assemblage. Few Mesolithic sites have a complete absence of this material (Wickham-Jones pers comm). Some broad-blade material was present at Howick outside the main structure, but at East Barns lithic material was almost solely confined within the hollow. A test pitting survey undertaken as part of the initial evaluation revealed a surprisingly thin scatter of largely narrow-blade lithic material. It is therefore likely that the homogeneous narrow-blade assemblage associated with the house was created in relative isolation within a sparsely populated landscape with little chance of admixture with earlier material. This gives weight to the notion of the inhabitants of East Barns representing a pioneer population associated with a secondary colonisation of Britain.

\subsubsection{Spatial analysis}

\section{Debitage}

All five plotted debitage categories (cores, blades, flakes, rejuvenation flakes and fine fraction) gave very similar distributions (Illus 16-19). Given the overall nature of the assemblage, all three of the recognised occupation horizons directly associated with the structure produced significant material in relatively proportional quantities. These proportions were also replicated within the refuse deposit (C2573).
The majority of cores were recovered from the occupation horizons situated to the immediate north (C2535-2549) and south (C2564) of the house (Illus 16). A relative absence of cores from the activity area to the west of the house (C2561) was observed. This relatively discrete clustering of material suggests that the northern and southern areas were the probable focus for reduction on site. Smaller clusters of cores were also found within the house itself. These were recorded within the refuse deposit (C2573).

\section{Microliths and microburins}

The distribution of microliths corresponds closely with the majority of the other categories recorded within the in situ deposits (Illus 15). A tight cluster of varied forms occurred in the northern part of Occupation Horizon 2064. This is repeated within Horizon 2549, although in a more diffuse manner. Scalene triangles are present in all of the activity areas.

However, they only appear to dominate the westernmost horizon (C2561). Within the structure itself microliths are again found in respectable numbers, mostly in the form of scalenes. They are largely restricted to the eastern lenticular part of Refuse Deposit 2573. Ten microliths, including six scalene triangles, were recovered from the hearth (C2677) and other deposits located within the centre of the house.

Microburins and associated pieces were largely confined to the northern occupation horizon (C2535-2549), with occasional examples occurring within the other external horizon deposits. These artefacts appeared to be absent from within the structure itself, with the exception of four pieces recovered from the north-east corner of the house again occurring within Refuse Deposit 2573.

\section{Scrapers}

Scrapers were well distributed throughout the external occupation horizons (Illus 15). These tools were again recovered from the interior of the house, with two clusters located in the north-east and south-east. These were again found within the refuse deposit (C2573) located along the eastern perimeter of the structure. Two scrapers were also retrieved from the refuse deposit located within the centre of the house. 


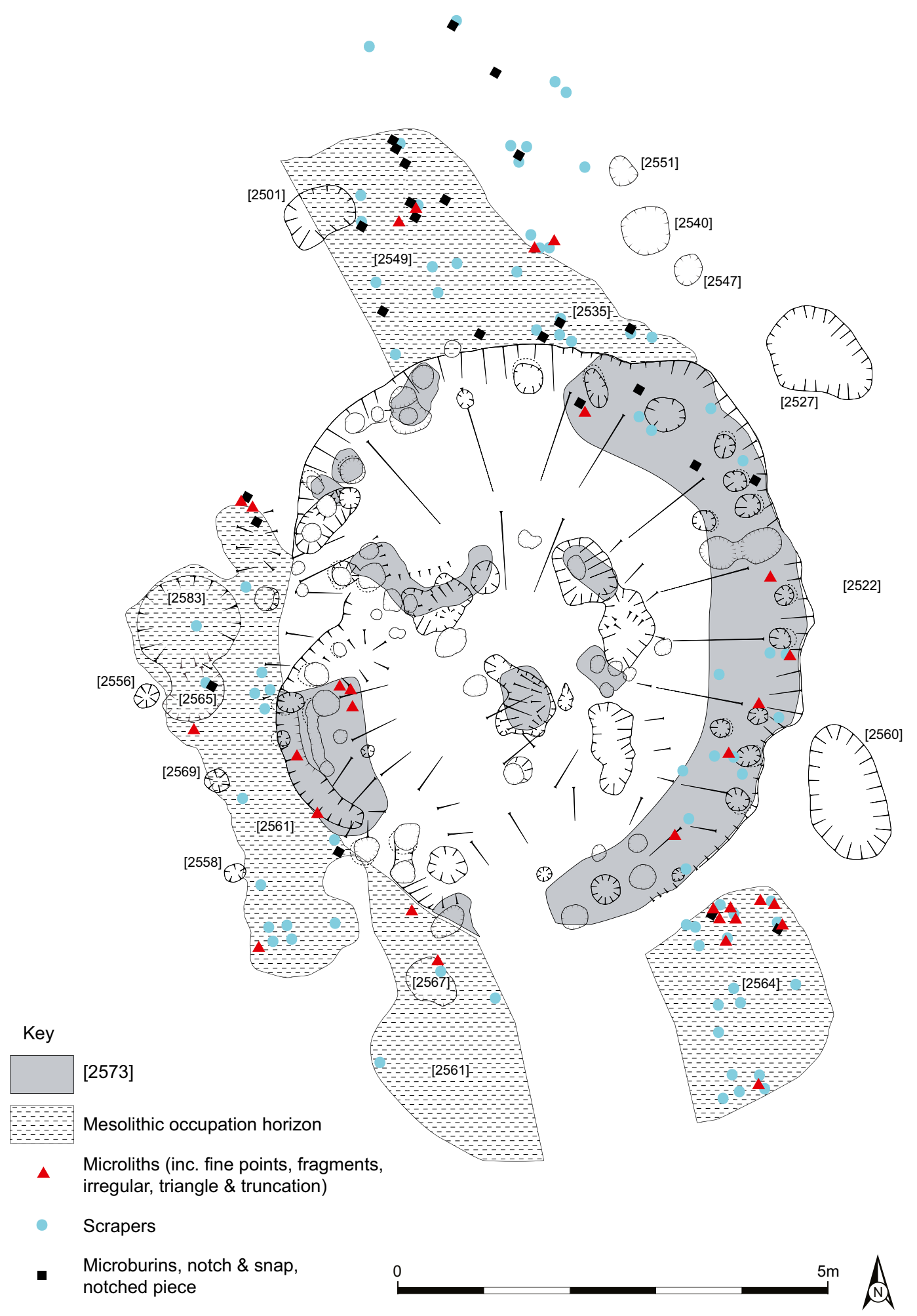

Illus 15 Distribution of modified lithic tools 


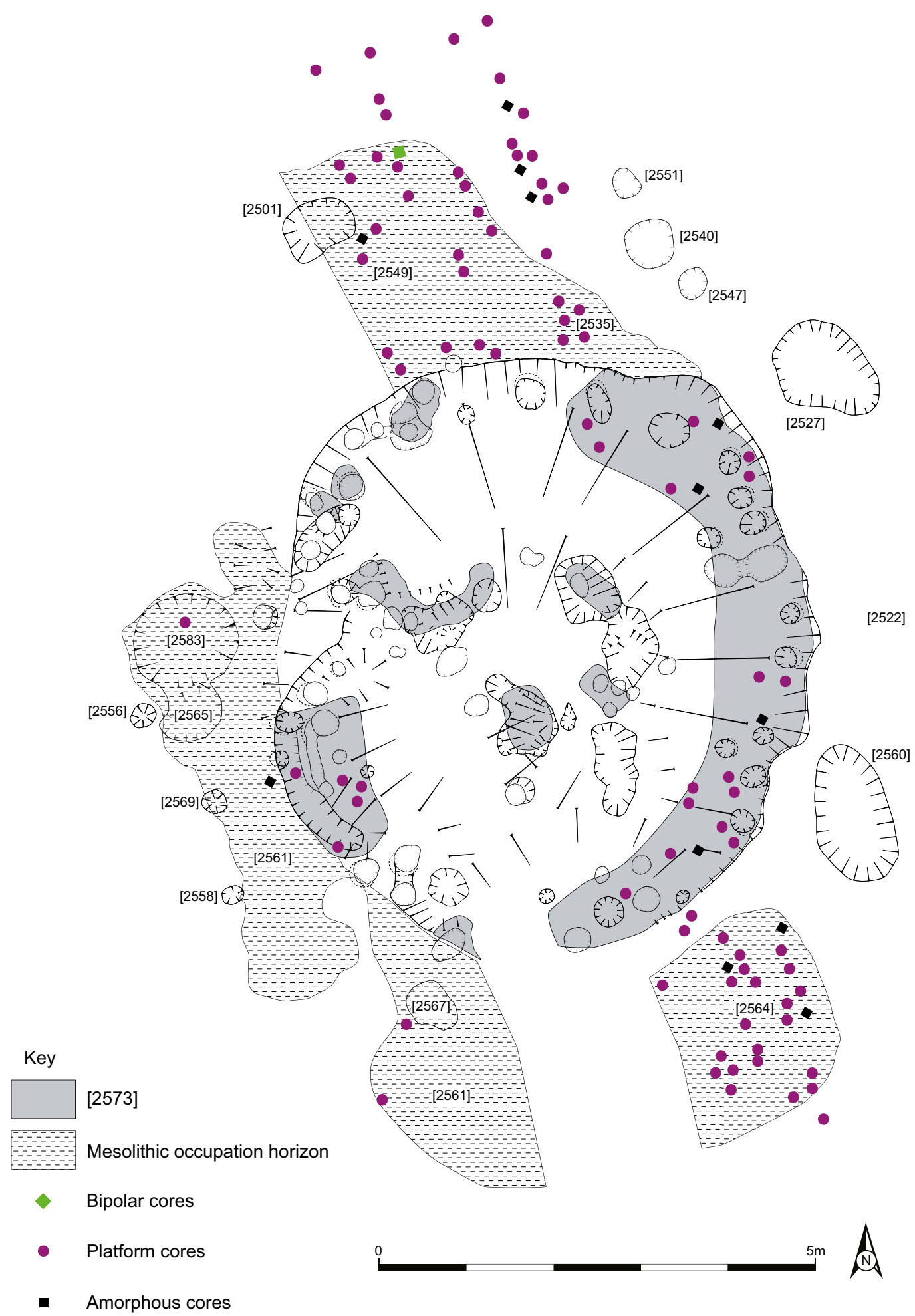

Illus 16 Distribution of core types 


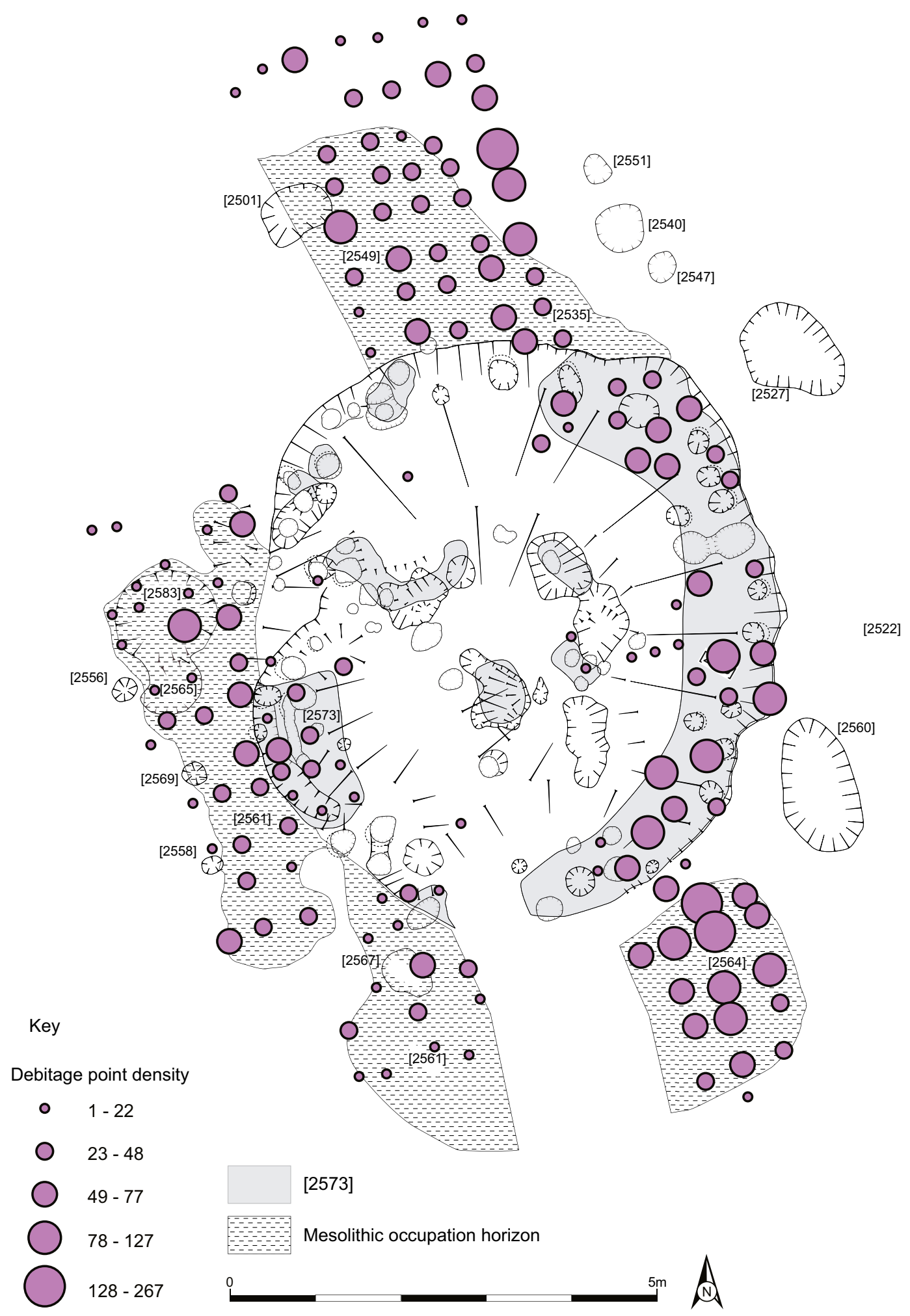

Illus 17 Distribution of debitage 


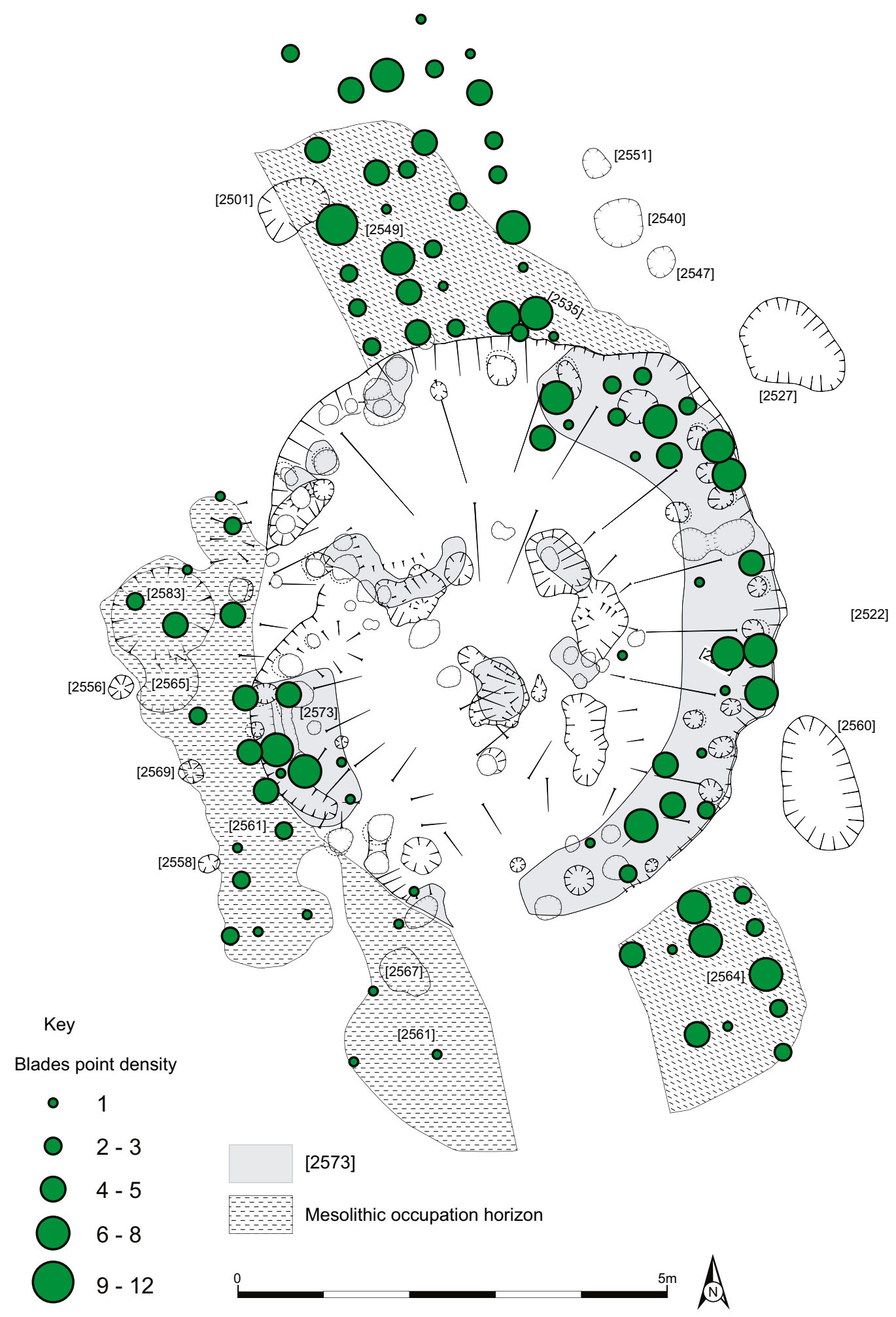

Illus 18 Distribution of blades 


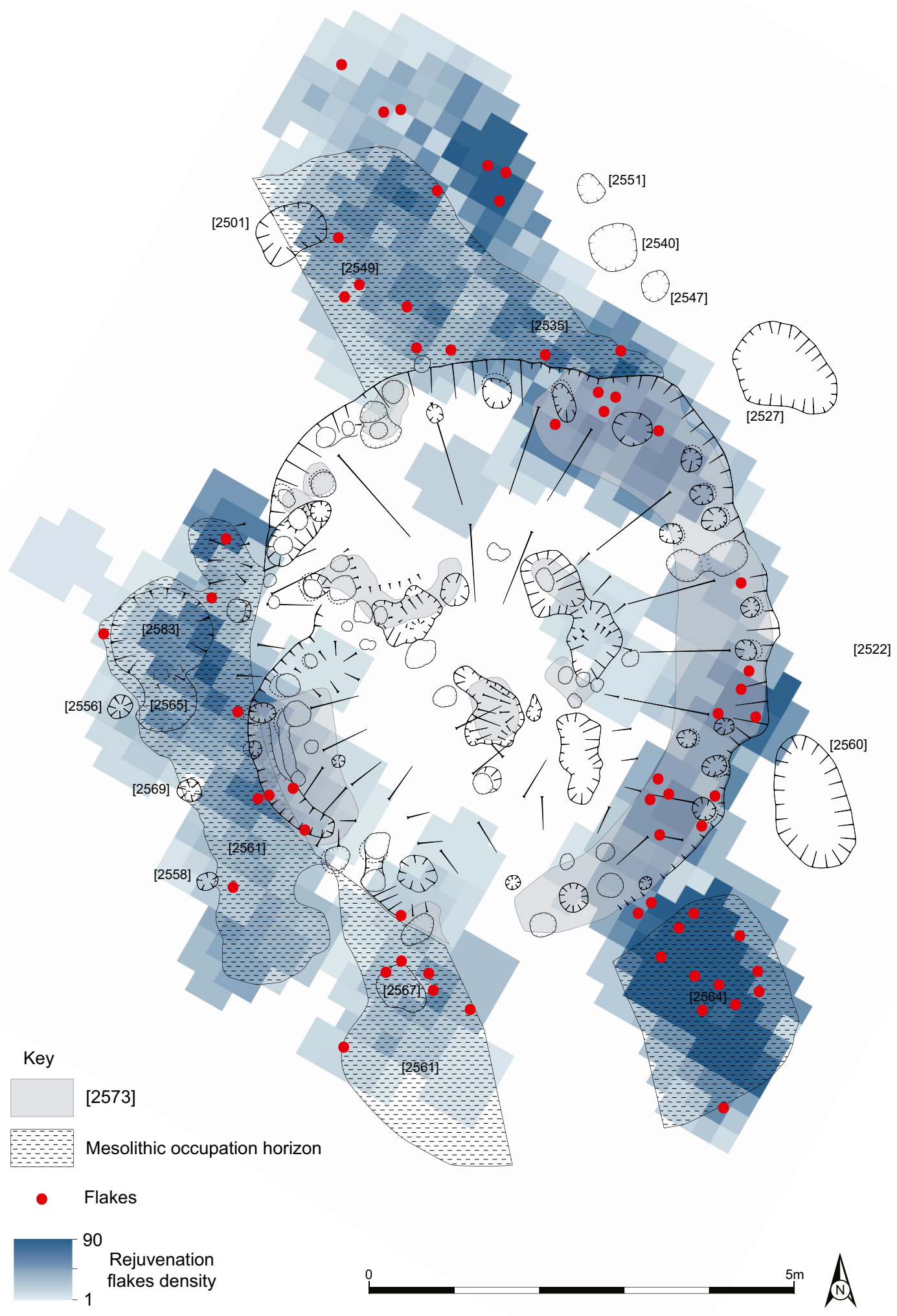




\section{Other tool categories}

These artefacts included points, retouched pieces, denticulates and knives. As with the other modified tool categories, their distribution appears to be largely restricted to the occupation horizons to the north and south-east of the structure. A small cluster of points is located within the southern half of C2564, with a cluster of retouched pieces occupying the northern part of the context. Retouched pieces are also fairly numerous within the northern horizon (C2549), together with a single knife and denticulate.

Within the house itself, the refuse deposit located along the eastern perimeter contains several points, retouched pieces and denticulates. The latter category appears largely confined to the southern half.

\subsubsection{Summary and discussion}

Illus 15 to 19 clearly show that the majority of the in situ lithic material including both modified and debitage classes was concentrated within the external occupation horizons and from within the refuse deposit within the interior of the house. This deposit also had a lithic-rich presence within the south-west corner of the house and occurred intermittently both within the central interior and north-west perimeter. The deposits and features associated with and surrounding the hearths also provided a substantial amount of lithic artefacts, again including both modified material and debitage.

Cores, blades, flakes, fine fraction and rejuvenation flakes have almost identical plotted distributions. All five categories exist in significant quantities both within the occupation horizons to the north and south of the house and from within the refuse deposit along the eastern and south-western interior perimeter. On the eastern perimeter a small yet significant gap is apparent within the distribution of the debitage (Illus 17). The presence of numerous cores and other debitage within the refuse deposits and fills of the interior suggests that blade/flake production was also occurring within the house itself. This activity was also noted within the structure excavated at Mount Sandel (Woodman 1985: 141).

The distribution of the debitage within the house most probably represents the waste from three working zones immediately surrounding the central hearth pits to the north-east, south-east and south-west (Illus 17) of the interior. Interestingly, cores of all types are largely absent from the west of the house. Core reduction was therefore apparently restricted to the north-eastern and south-eastern parts of the house and its associated external occupation horizons.

The distribution of scrapers and miscellaneous tool categories forms an interesting accompaniment to that of the debitage. Several large, diffuse clusters of scrapers are visible within the external occupation horizons, showing that these were the primary areas of usage. However, scrapers also appear in significant numbers within the house. These appear restricted to two separate clusters, one in the north-east and one in the south-east of the refuse deposit. This appears to be replicated by the general distribution of the miscellaneous tool categories. The distribution of these artefacts implies that domestic tasks such as the scraping of hides etc also took place within the house in addition to general tool manufacture and curation (Illus 15).

The distribution of microliths also appears to follow the pattern observed in the categories above. Numerous examples were recovered from the external occupation horizons and the internal refuse deposits as well as from the waste pits both inside and outside the house. It would appear from the distribution plots that scalene triangles are the most numerous categories found within the refuse deposit. This distribution is especially marked in the north-east of the house, where other categories are almost entirely absent. The scalenes and indeed most of the other microlith categories appear to occur in tight clusters. This suggests evidence of tool maintenance occurring within specific and possibly demarcated areas within the house.

Microburins and associated categories are almost totally absent within the house, with the exception of several notched pieces found in the north-east corner. These artefacts appear largely restricted to the occupation horizon situated immediately north of the house, with occasional examples occurring within the other areas. Given that these artefacts are associated with microlith manufacture and that numerous microliths were recovered from the interior of the house, it would be sensible to conclude that the majority of microlith manufacture was conducted outwith the house. 
The in situ lithic material recovered from the house displays a primarily annular distribution directly related to the build-up of Refuse Deposit 2573 (see Section 4.7, Discussion). This deposit was formed by the remains of domestic refuse and lithic manufacture/maintenance which had fallen through the soft plant flooring of the house and been allowed to accumulate out of sight. It is likely that the distribution of lithic material therefore represents 'conversational' patterns of disposal (Binford 1978; Woodman 1985: 141). Such a refuse deposit would likely aggregate around the seated positions of the inhabitants around a central hearth. It is also likely to accumulate within the rear recesses of the structure as waste is tossed behind the seated individual away from the active areas of the house. This would account for both the high amount of general waste and the variety of tool categories recovered from this deposit. This method of disposal, though far from an ideal form of housekeeping in a modern sense, would leave the majority of the house free from debris. The lithic material recovered from in and around the hearth pits suggests that material was also thrown into the fire pits from people facing it. This pattern of disposal is also seen at Echline Fields (Robertson et al 2013: 93) and at Howick (Pedersen 2007). At the former, concentrations of lithic material were recovered not only from the fills of internal pits and post holes associated with the primary occupation but also from around the central hearth feature.

During the primary occupation phase at Howick, a similar complex of formal tool types and debitage was observed, forming three clusters around a prominent central hearth. Although these were not associated with a refuse deposit, their general distribution within the house was also thought to reflect discrete activity areas. As at East Barns, the distribution of cores mirrored that of blades and other debitage. This was also repeated within the modified tool categories such as microliths and scrapers.

The lack of lithic material found in the north-west interior of the East Barns house possibly implies a separation of activities occurring within the house. This area is occupied by the platform and appears to have avoided the signs of erosion associated with repeated movement and footfall present within the southern half of the structure. It is therefore highly likely that the north-western part of the house was used for sleeping quarters or other less utilitarian activities.

In summary, the spatial analysis has revealed that the majority of lithics retrieved from the in situ deposits within the house reflect the gradual accumulation of waste material directly derived from both the direct manufacture of blades and flakes and from other activities such as the maintenance and utilisation of tools. These accumulations of material reflect an annular pattern of disposal from three discrete working areas located to the north-east, south-east and south-west of the central hearth.

To the immediate north, south and west of the house lay several occupation horizons in which similar distributions of lithic material to those found within the house were in evidence. This suggests that a similar set of activities were also practised outside the house.

\subsection{Discussion}

The excavation of the Mesolithic house at East Barns produced a significant lithic assemblage obtained largely from a series of spatially limited, well-defined and securely dated contexts relating to a late 9th millennium BC occupation.

A key factor in the examination of this material was the study of its 'sister' assemblage at Howick, Northumberland (Pedersen 2007). The author makes no apologies for focusing on this site for many direct comparisons, given the geographical proximity and the similar natures of the sites. The two sites were investigated almost in tandem, which allowed for information to be shared and terms and descriptions standardised.

The material produced at East Barns can be characterised as a narrow-blade/scalene triangledominated assemblage. As such, it appears to fit into the small but growing group of sites associated with early dates relating to the $8-9$ th millennium вС (Saville 2004: 207). In addition to the assemblages associated with house structures at Howick (Waddington 2007), Low Hauxley (Pedersen 2016), Mount Sandel (Woodman 1985) and Echline Fields (Robertson et al 2013), one can add the small-scale excavations at Cramond, Edinburgh $(8400 \mathrm{cal} \mathrm{BC})$ (Saville 2008; Engl 2012; Lawson et al forthcoming).

The increasing number of narrow-blade 
microlithic assemblages associated with early dates has obvious ramifications with regard to the traditionally prevailing model (Jacobi 1976) of an Early Mesolithic characterised by broad-blade industries and a narrow-blade industry denoting the later Mesolithic. Saville (2008: 213) has already questioned the relevance of this model for interpreting lithic assemblages within the 9th millennium of northern Britain. The reassessment for the emergence of narrow-blade technology within the north-east of the British Isles has begun to take a more formal shape through the work of Waddington (2007; et al 2007b; 2014) and Waddington \& Bonsall (2016), whose hypothesis on a population diaspora initiated by the inundation of the North Sea Basin includes narrow-blade technology as part of a spreading culture complex first emerging in south-east Scotland and north-east England. This would appear at this current time to be well supported by the existing evidence as more early, narrow-blade-associated house sites such as East Barns and Echline Fields join the archaeological record.

As with the aforementioned assemblages, the East Barns material is characterised by the localised procurement of abundant and good quality lithic raw materials. This appears to have been an essential part of subsistence activities practised throughout the Early Mesolithic. Mesolithic populations in Scotland are known to have used a wide range of lithic raw materials, usually but not exclusively as a supplement to flint (Finlayson 1990a; Saville 1994). The dominance of flint (85\%) within the assemblage is slightly less than at other settlement sites of the period such as Mount Sandel in Northern Ireland (99\%) (Woodman 1985), Newton, Islay (99.9\%) (McCullagh 1989), Howick, Northumberland (98.9\%) (Waddington 2007) and Echline Fields, on the Firth of Forth. At Echline Fields good-quality chert was the dominant raw material (Robertson et al 2013: 107). This may reflect issues of local availability, combined with the relatively good quality and utility of the supplementary materials, which allowed the knappers of East Barns to produce modified tool types in chert, chalcedony and quartz. These materials were also obtained from the same local sources as the flint and it seems unlikely that Mesolithic collectors would ignore the presence of such serviceable materials in a concerted search for flint, as this would have had undoubted cost/ benefit implications. This may explain in part why supplementary raw materials are usually present within flint-dominated assemblages of the northern British Mesolithic.

Nevertheless, a Mesolithic preference for flint as a working material can be seen in its ubiquity on Mesolithic sites, even where the material is locally scarce (Saville 2004: 185). Flint is present within the lithic assemblages of areas such as central Dumfries and Galloway (Finlayson 1990a) and the Upper Tweed Valley (Warren 2005), where good quality chert forms the mainstay of many assemblages. On the Hebridean Isle of Rhum flint actually dominates the Mesolithic assemblages even though no local flint is presently known from the island's beaches and good-quality bloodstone and chalcedonies are readily available (Finlayson 2004; Wickham-Jones 1990).

Flint would therefore appear to head a hierarchy of utilised raw materials within the Mesolithic. These materials produce the highest frequencies of microliths and blades, followed by chert, which produces a higher frequency of flakes, then chunks, with finally quartz not producing conventional blades (Finlayson 2004: 223). This appears to be well illustrated by the evidence from East Barns. However, although flint produced the most blades and microliths in number, both chert and chalcedony produced a slightly higher percentage of these artefacts compared with the total proportions of each material present within the assemblage. This again can probably be explained by the generally high quality and small nodule size of all raw materials found within the area.

As already mentioned, the exploitation of flint and other raw materials in the Mesolithic of northern Britain was undertaken on a local and perhaps regional level. The Southern Uplands chert present at East Barns is the major component of Mesolithic assemblages across Dumfries and Galloway, the Forth Valley and the Upper Tweed Valley, where it was possibly mined in the Mesolithic (Warren 2003). Flint occurs to a lesser degree, though it appears intensively used within these assemblages (Finlayson 1990a). This flint is presumably derived from coastal deposits such as those found at East Barns. Finlayson's model (Finlayson 1990a; 2004: 224) of differentiating lithic economies through 
the proportions of raw materials and the assumed high value ascribed to those such as flint, can be applied with regard to coastal flint-rich sites such as East Barns and Howick and inland areas such as the Tweed Valley, where chert dominates. Finlayson implies that where flint is embedded into the site economy as a local material within the mobile round', a steady fall-off in such a round would account for a lower proportion of flint on sites furthest away from the source of the high-value raw material. This in turn would lead to generally higher visible rates of curation (Finlayson 2004: 224). The presence of such a mobile round in the vicinity of East Barns is still to be recognised due to a current lack of fieldwork within the surrounding area.

With the high value placed on flint, it is probable that the presence of a reliable source of this material was a primary concern within the Mesolithic economy. This would have been a major draw in attracting people to inhabit sites such as East Barns.

The range, quantity and types of raw material encountered on the site are typical of many of the more substantial and stratified Mesolithic coastal sites excavated in northern Britain. It is notable for the general quality of its supplementary raw materials which, though smaller than flint in number, were evidently obtained from the same sources and were of sufficient quality to produce a similar range of artefacts such as conventional blade blanks and retouched tools.

The assemblage at East Barns shows the hierarchical on-site reduction of a variety of local nodular raw materials. These were worked in a variety of ways, with platform reduction being the most important. A significant bipolar presence was also registered. This technique appears to have been used to work less tractable materials such as quartz, and extend the productivity of the higher quality flint and cherts. Cores of all types were worked fairly intensively, with numerous multi-stage examples.

Blade cores were the predominant platform type, which, coupled with the information gleaned from the blank sample, suggests that blade manufacture was an important if not primary focus of manufacture undertaken on site. This was also recognised at both Howick and Echline Fields.

Cores were heavily maintained, and a range of rejuvenation flakes were produced, maintaining the platform and core face. The majority of cores appear to have been abandoned due to size constraints. Other factors influencing abandonment, such as technical problems and naturally occurring flaws within the material itself, were also observed.

Knapping involved the creation of simple platforms on opened nodule surfaces. In many cases the angle of the unopened nodule was considered sufficient to support direct knapping on the cortical surface itself. Platforms were maintained by the simple trimming of the edge to remove lips and other irregularities.

A direct soft-hammer technique appears to have been the main form of reduction employed within the assemblage. The bulbs of percussion were a mix of diffuse and pronounced types, with the former in the majority. Other indicators of the direct application of soft-hammer technique are present in the high number of narrow and crushed blade/ flake platforms.

As with the assemblages at Howick and Echline Fields, all stages of the chaîne opératoire were present at East Barns. However, significant differences between the assemblages are apparent. The East Barns assemblage revealed evidence for production, use, curation and discard. This was recovered from both external occupation horizons and internal refuse deposits. At Howick, external horizons were absent, with primary reduction thought to occur close to the area of collection. It is thought that the debitage recovered from the internal deposits at Howick resulted almost solely from tool curation and replacement (Waddington 2007: 54). At Echline Fields, lithic material was also recovered from deposits within the excavated structure but was restricted externally to pit fills.

It is possible that such inter-site differences may be the result of differing taphonomic processes. In contrast with both Howick and Echline Fields, the position of the East Barns site within a natural hollow led to the formation of a protective covering of colluvium. This in turn protected the in situ deposits from the erosional effects of modern farming practices.

At East Barns the distribution of lithic material both internally and externally was relatively consistent. A similar set of activities, including core reduction, appeared to be practised both internally and externally. An annular pattern of disposal was observed within the house, obtained from three 
discrete working areas located to the north-east, south-east and south-west of the central hearth pits. This distribution pattern around a central hearth is replicated to a certain degree in the primary occupation phase at Howick.

The assemblage at East Barns produced a wide range of formal tool and microlith types with a high incidence of scalene triangles, microburin/ notched bladelets and scrapers. These tools were used in a range of activities, including hide working, butchering, tool/ornament manufacturing and tool maintenance. The range of microliths in particular was very similar to that produced at Howick. At East Barns microliths accounted for $1.52 \%$ of the assemblage compared with $2.1 \%$ at Howick and $3.8 \%$ at Echline Fields. Though this initially appears rather low, the combination of a protected site and intensive artefact recovery has obviously helped reduce the relative percentage in comparison to the other sites, where much of the production evidence has been removed.

Scalene triangle microliths dominated, accounting for $46.7 \%$ of the total number of microliths. Scalenes were also the dominant form at the house sites of Howick and Mount Sandel. Surprisingly, these artefacts were almost absent at Echline Fields, being supplanted by crescent forms. However, the high number of unrecognised broken microliths present at this site may again have skewed the data set.

Microburins, notched bladelets and notch-andsnap artefacts are linked with the manufacture of scalene triangles and other microlith categories (Wickham-Jones \& McCartan 1990: 100; Saville
2005: 113). The 148 pieces recovered at East Barns would suggest that the production of microliths was an important undertaking. The relative scarcity of such artefacts at Howick and Echline Fields is again most probably due to the absence of in situ working areas surviving at these sites.

In the study of the Howick assemblage, Waddington has identified a tentative 'signature' for lithic assemblages obtained from Mesolithic settlement sites (Waddington 2007: 55) based on five characteristics. These consist of a wide range of tool and microlith types, an absence or low incidence of microburins, a disproportionately large number of formal tool types compared to primary and secondary debitage, and finally a large proportion of tools broken before discard. The East Barns assemblage displays a similar signature, albeit with the presence of numerous microburins and a lower number of formal tool types. As previously explained, factors of site morphology and taphonomy are again the most obvious explanation for these discrepancies rather than absolute differences.

Due to the fortuitous nature of its location and the subsequent survival of its external working areas, East Barns probably presents a more complete assemblage than any of its contemporaries. The presence of large numbers of primary and secondary debitage therefore makes East Barns a link between the substantial house sites of the 9th millennium and the later large knapping sites such as Kinloch, Rhum (Wickham-Jones 1990: 99) where significant structural evidence survives but without the robust nature of those sites on the Forth littoral. 